\title{
Grouting Treatment of Water and Mud Inrush in Fully Weathered Granite Tunnel: A Case Study
}

\author{
Jiandong Niu $\mathbb{D}^{1},{ }^{1}$ Yong Sun, ${ }^{1}$ Bin Wang $\mathbb{D},{ }^{1}$ Keneng Zhang, ${ }^{2}$ Youhan Huang, ${ }^{3}$ Shiwu Huang, \\ Jiaqin Yu, ${ }^{5}$ and Liangliang Qiu ${ }^{6}$ \\ ${ }^{1}$ School of Civil Engineering, Central South University, Changsha 410000, China \\ ${ }^{2}$ School of Geosciences and Information Physics, Central South University, Changsha 410000, China \\ ${ }^{3}$ Hunan Institute of Construction Technology, Changsha 410000, China \\ ${ }^{4}$ Guangxi Communications Investment Group Co., Ltd., Guangxi 530000, China \\ ${ }^{5}$ China Railway No. 5 Engineering Group Co., Ltd., Changsha 410000, China \\ ${ }^{6}$ Changsha Hengde Geotechnical Engineering Technology Co., Ltd., Changsha 410000, China
}

Correspondence should be addressed to Jiandong Niu; niudong@csu.edu.cn

Received 8 September 2020; Revised 19 October 2020; Accepted 26 October 2020; Published 26 November 2020

Academic Editor: Yanlin Zhao

Copyright (C) 2020 Jiandong Niu et al. This is an open access article distributed under the Creative Commons Attribution License, which permits unrestricted use, distribution, and reproduction in any medium, provided the original work is properly cited.

\begin{abstract}
When mountain tunnel passes through completely weathered granite strata, water and mud inrush is easy to occur, causing casualties and economic losses. Grouting is a common and effective treatment method for water and mud inrush disaster. The current existing researches focus on theoretical analysis, numerical simulation, and laboratory test, and the researches based on the field of engineering application are few. Based on the fully weathered granite tunnel of Junchang tunnel in Guangxi, this paper studies the grouting treatment of water and mud disaster in the fully weathered granite tunnel. This paper first introduces the geological and hydrological conditions of Junchang tunnel in order to understand the causes of water inrush and mud inrush. Then, the treatment method of full-section curtain grouting is introduced. During the grouting, the combination of exploration and injection is adopted. According to different hydrological conditions, different kinds of grouting materials are adopted. After grouting is completed, Transient Electromagnetic Methods, water inflow analysis, borehole investigation, and P-Q-T method are used to evaluate the grouting effect. According to the reaction of the detection results, the weak part of grouting can be supplemented to improve the grouting quality. The results show that the curtain grouting is effective for the treatment of water-mud inrush disaster in the fully weathered granite tunnel. This study provides a reference for the treatment of water and mud inrush in other similar tunnels.
\end{abstract}

\section{Introduction}

In the process of tunnel excavation, water and mud inrush often occurs [1-3]. Although people have made considerable progress in understanding the mechanical properties of rock mass [4-20] and theories and technologies of tunnel excavation and support have been greatly developed [21-25], it still cannot completely contain the occurrence of water and mud inrush. Every year, water and mud inrush still causes a large number of equipment losses and casualties [26]. For fully weathered granite, it is widely distributed all over the world $[27,28]$, with fractures developed and poor water stability [29-31]. Tunnels dug in this formation are often exposed to huge risks of water and mud influx [32], which is a great challenge for tunnel engineers. Grouting method has been more and more widely used as an effective means of water plugging and reinforcement [33-35]. At present, curtain grouting with full section is a common and effective method for treating water-mud inrush in tunnels.

In terms of the mechanism of tunnel water and mud inrush, Liu et al. $[36,37]$ established a new model of seepage and erosion to describe water inrush based on the classical theories of solute transport and fluid dynamics in porous media, and the relative critical conditions for water inrush were proposed through experiments. Liang et al. [38] and Zhang et al. [39] analyzed the changing rules of stress and 


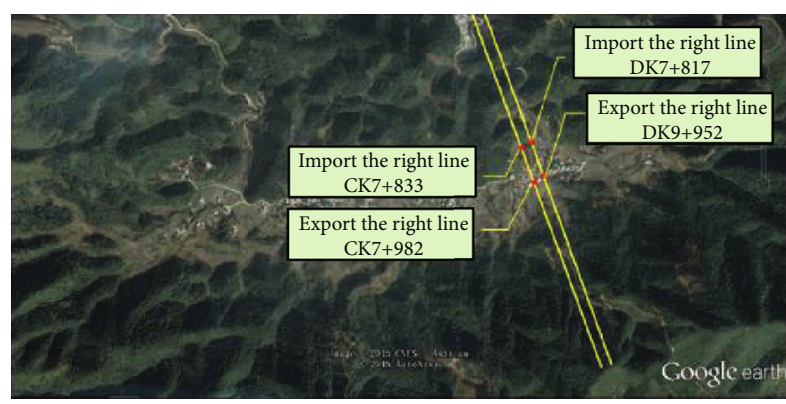

FIGURE 1: Layout of the Junchang tunnel.

displacement as well as the coupling effects of failure and leakage during tunnel excavation and divided the process of water and mud inrush into several stages. Yang et al. [40] showed that the essence of water and mud inrush is that when the cohesion of soil decreases gradually with the increase of pore ratio, until the movement of soil particles cannot be restricted, the soil particles and groundwater form mud and flow out. Zhao and Zhang [41] carried out a series of experimental studies using a rotating viscometer and a simulation model. The results showed that the viscosity of mud inburst in the mud did not depend on the particle size but on the moisture content. Li et al. [42] studied the plugging mechanism and method of water inrush in karst passages through numerical simulation, laboratory experiments, and engineering and analyzed the changing law of water flow velocity.

In the tunnel water and mud inrush grouting treatment, Zou et al. [43] regarded cement grout as the importance of Bingham fluid in the study of water phase in rock grouting. The numerical simulation results showed that water meeting significantly affected the pressure distribution and grouting penetration in fractures, especially under the grouting hardening condition. Stromsvik [44] studied the grouting treatment of a tunnel in Norway, proving that pregrouting is effective for the prevention and control of tunnel water disaster. Shi et al. [45] and Liu et al. [46] studied the influence of grouting layer thickness on water plugging effect through experiments, numerical simulation, and other methods and determined a grouting layer thickness that gives consideration to both safety and economy. Zheng et al. [47] conducted a number of tests, including strength, permeability, and flushing resistance, to assess the impact of filling rate (GFR), curing age, and water velocity on the grouting effect in order to propose the best material parameters for grouting. Lee et al. [48] showed through laboratory experiments that the waterproofing efficiency of grouting increased with the decrease of grouting hole size and W/C. Tani and Stille [49] and Zhang et al. [50] conducted a large number of grouting tests to evaluate the influence of different grouting parameters on the grouting effect of tunnels.

However, domestic and foreign scholars focus on the mechanism of water and mud inrush disaster, and the researches on grouting treatment of water-mud inrush mainly rely on theoretical analysis, numerical simulation, and laboratory test. However, there are few relevant researches based on field grouting treatment.
Based on Junchang tunnel, a typical weathered granite tunnel, and the grouting treatment of its water-mud inrush, this paper proposes a set of effective grouting treatment methods: the combined method of drilling and detection is adopted to carry out customized grouting, for different structures using four different slurry; the grouting method of the latter sequence grouting hole is dynamically optimized according to the feedback result of the drilling. After grouting, Transient Electromagnetic Methods, borehole investigation, and $\mathrm{P}-\mathrm{Q}-\mathrm{T}$ analysis are used to detect the grouting effect, and the weak parts are supplemented to improve the grouting quality.

\section{Engineering Background}

2.1. Engineering Summary. Junchang tunnel located in Cenxi Municipality, Guangxi Province, is the project site shown in Figure 1 . The tunnel is designed as a separated closely spaced tunnel, the center line distance of the two tunnels is $30 \mathrm{~m}$, the clear distance is $17 \mathrm{~m}$, and the three-step method is adopted for excavation. The single length of the tunnel is about $4.3 \mathrm{~km}$, and it is an extralong highway tunnel.

When excavating to the lower part of Shanxin Village, two severe water and mud inrush disasters occurred. The first time is when the tunnel is excavated to DK7+963; a mud inrush disaster occurred on the right side of the tunnel face. In the initial stage of the disaster, the flood is mainly mud, and then, the flood is mainly water. The cumulative amount of mud is about $2900 \mathrm{~m}^{3}$, and the maximum water inflow is about $150 \mathrm{~m}^{3} / \mathrm{h}$. The outburst of mud led to internal collapse of the surrounding rock of the tunnel, and a collapse pit with a diameter of $12 \mathrm{~m}$ and a depth of $7 \mathrm{~m}$ appeared on the front surface of the tunnel face. The second time is when the tunneling reached DK7+939; water and mud gushing occurred on the tunnel face, with a total amount of about $2500 \sim 3000 \mathrm{~m}^{3}$, leading to the initial support cracking, deformation, and a large area of surface collapse. As shown in Figure 2, it greatly delays the construction progress and brings bad influence on local residents' life and regional ecological environment.

The tunnel in this section is surrounded by mountains and flat in the middle, forming a miniature basin, which provides a powerful water-catchment terrain for water and mud inrush. The stratum is mainly composed of highly weathered and fully weathered mixed rock, and the rock mass is extremely broken. The composition of the rock mass is mainly quartz dike and granite. The rock mass is broken, and joints and fissures develop, providing a water channel for water and mud inrush. At the same time, the tunnel site area belongs to the humid monsoon climate area in the central tropical mountainous area of Asia, with abundant rainfall, concentrated rainfall and high intensity, providing water supply conditions for water and mud inrush. The combined action of the above three factors leads to the high intensity and great harm of the water and mud inrush of the tunnel. In order to ensure the smooth excavation of the tunnel, the full-section curtain grouting method is used to block water and reinforce the tunnel. 

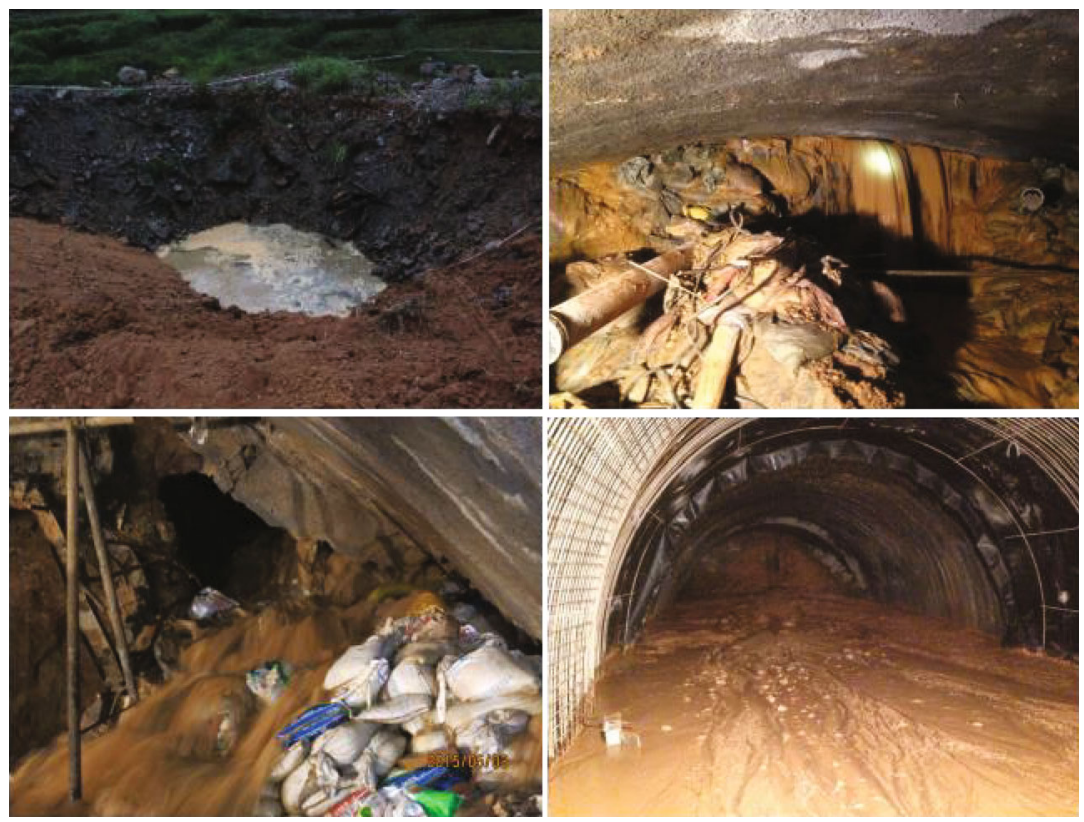

Figure 2: Disaster caused by water and mud inrush of Junchang tunnel.

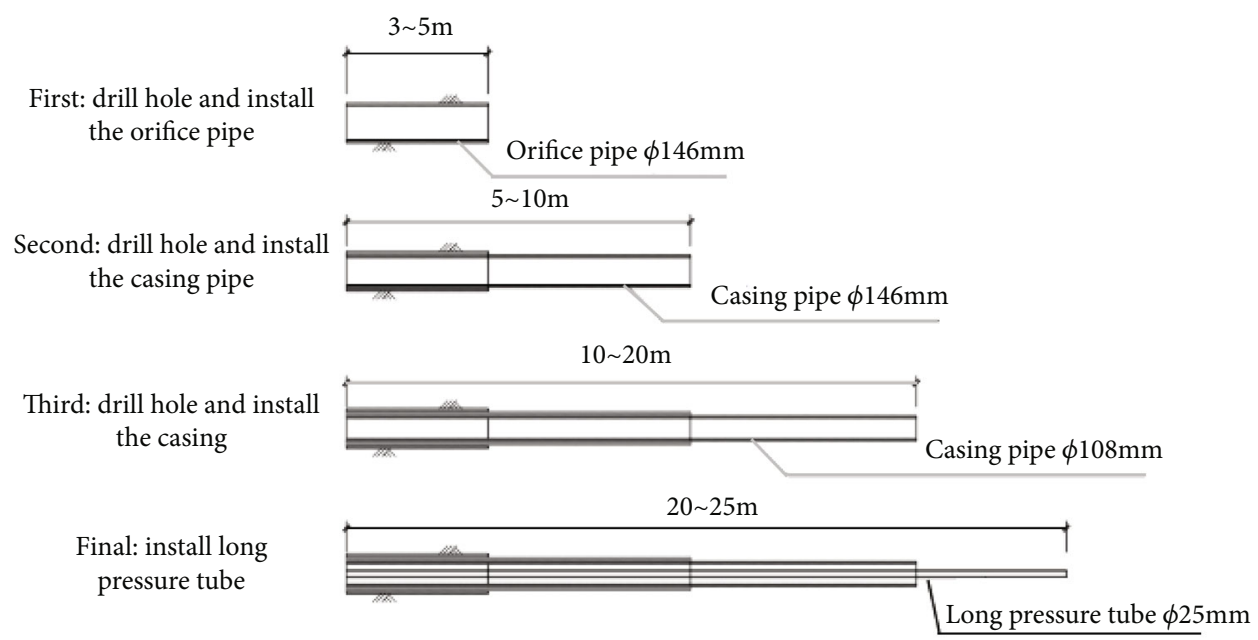

FIGURE 3: Schematic diagram of section drilling.

2.2. Geological Conditions. The tunnel site is located between Caledonian fold group and Yanshanian Shuiwen syncline in the middle and low mountain landform area of structural erosion type in the southeast of Guangxi. Due to the longterm tectonic action and surface water erosion, the terrain is undulating greatly, and the mountain slope is steep. The terrain has a parabolic shape that is high in the middle and low on both sides. The vegetation on the surface is lush, mainly covered by quaternary residual slope deposits, partially exposed by weathered mixed rocks, relatively developed joints and fissures in rock mass and fractured rock mass.

The outcropping strata are quaternary alluvial-diluvial $\left(Q_{\mathrm{a} 1+\mathrm{P} 1}\right)$ and residual slope $\left(Q_{\mathrm{e} 1+\mathrm{D} 1}\right)$ overburden and Lower Paleozoic Caledonian (Pz1 $\gamma 3)$ bedrock.

\subsubsection{Quaternary Overburden (Q)}

(1) Quaternary Alluvial-Diluvial Layer $\left(Q_{\mathrm{a} 1+\mathrm{P} 1}\right)$. It is mainly composed of pebbles, boulders, and silty clay, and its layer thickness varies greatly. It is mainly distributed on both sides of mountains, valleys, and rivers, usually in a zonal distribution.

(2) Quaternary Residual Slope Deposits $\left(Q_{\mathrm{e} 1+\mathrm{D} 1}\right)$. They are widely distributed in the surface layer of the mountain, mainly sandy cohesive soil, and there are local aggregates and blocks at the foot of the slope. Yellow and white, plastic, uneven soil quality, containing about $15 \%$ quartz sand, medium viscosity, and toughness.

2.2.2. Lower Paleozoic Caledonian (Pz1 $\gamma 3)$ Bedrock. It is mainly composed of mixed rocks formed under regional 


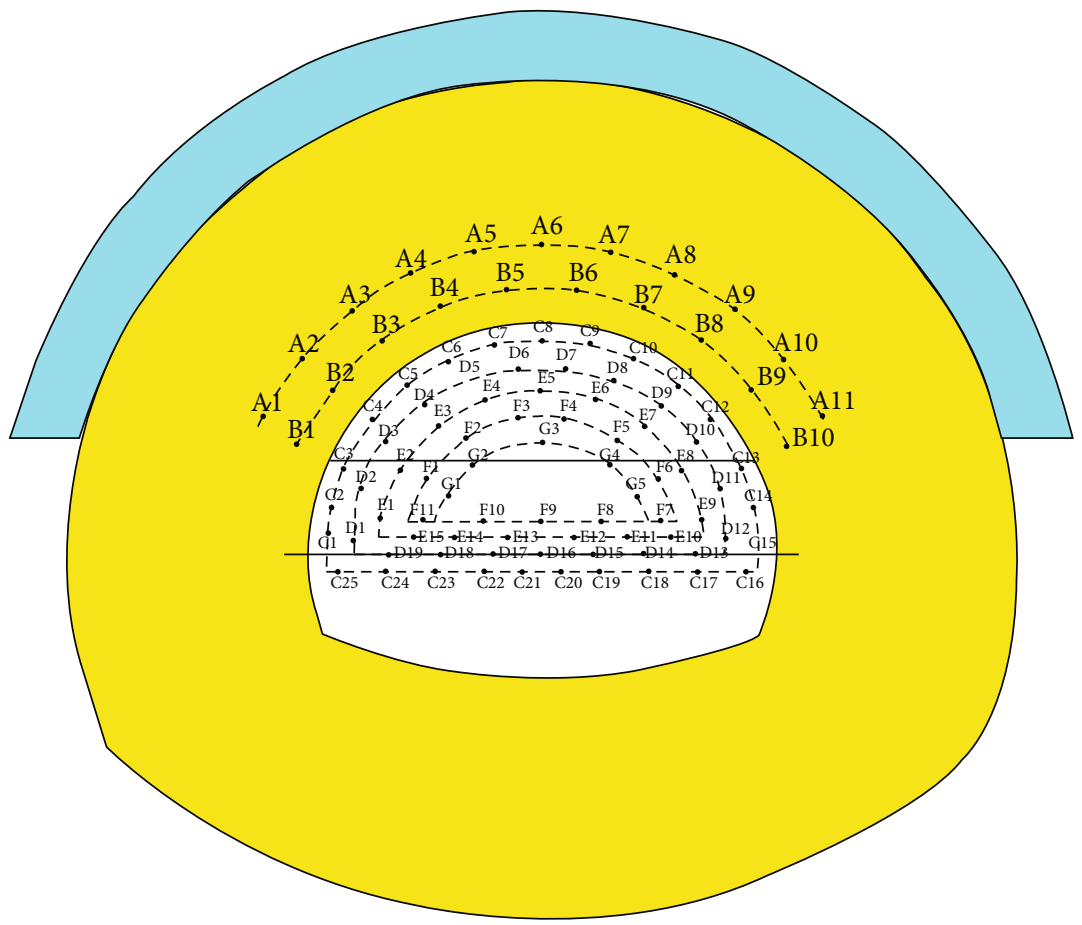

(a)

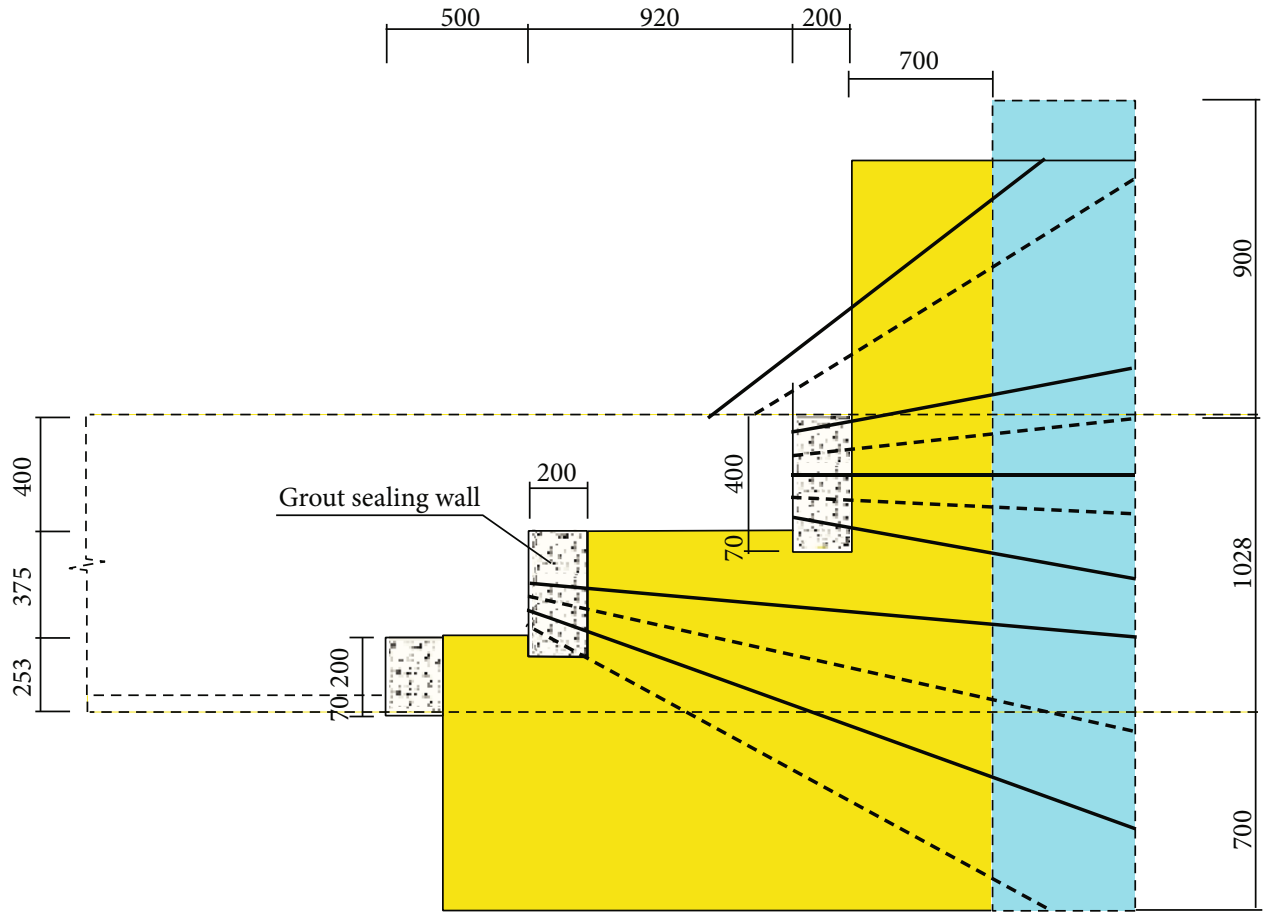

$9 \mathrm{~m}$ grouting curtain thickness

$7 \mathrm{~m}$ grouting curtain thickness

(b)

Figure 4: Schematic diagram of grouting curtain thickness: (a) cross section and (b) longitudinal profile.

metamorphism (such as gneiss granite, granitic gneiss, gneiss, and quartzite). The lithology is close to granite, and intrusive dykes exist locally. The mineral compositions are mainly quartz, feldspar, and mica. The mineral grains are in the form of medium to coarse grains. After metamorphism and crystallization, the mineral grains are in the form of 


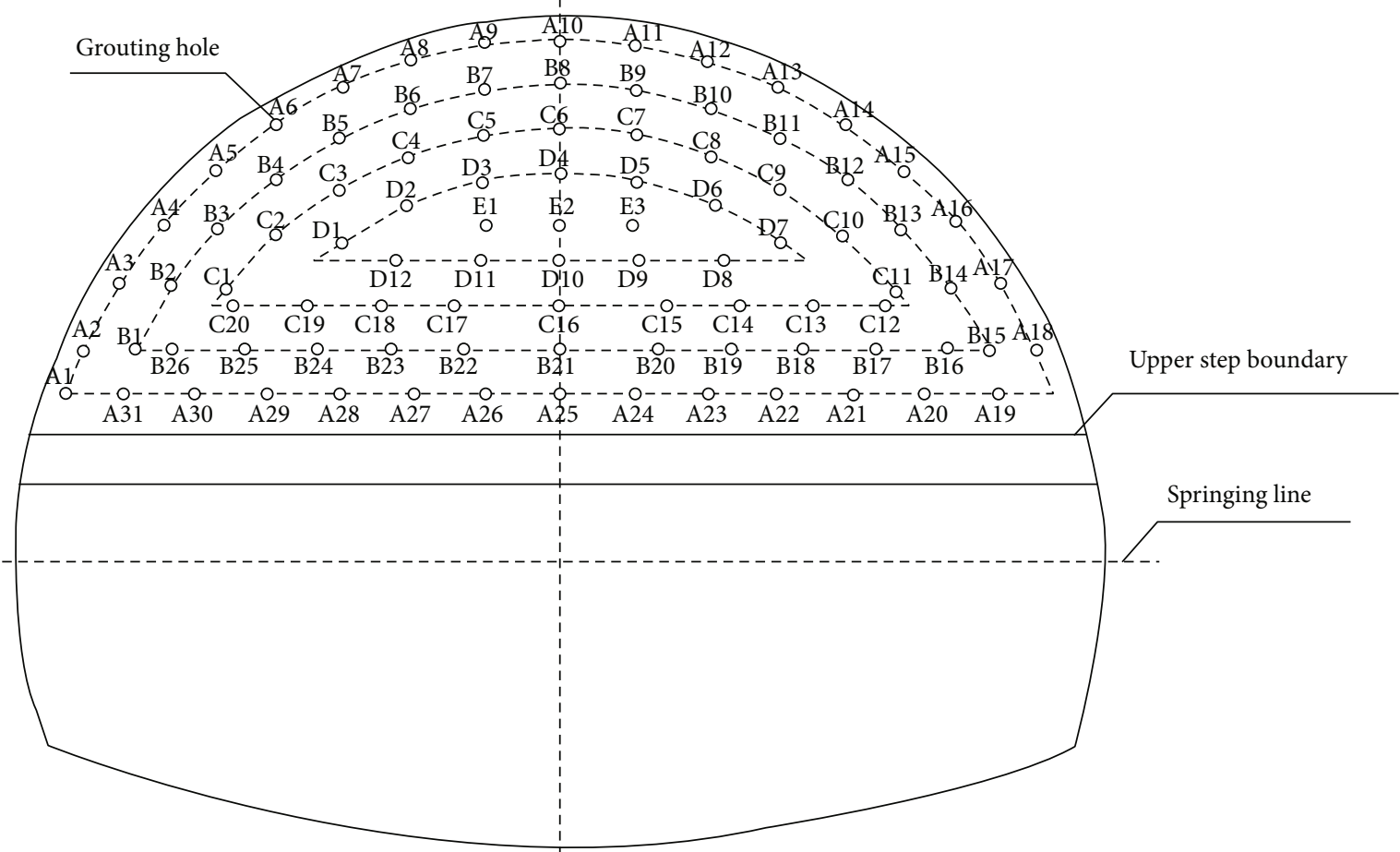

(a)

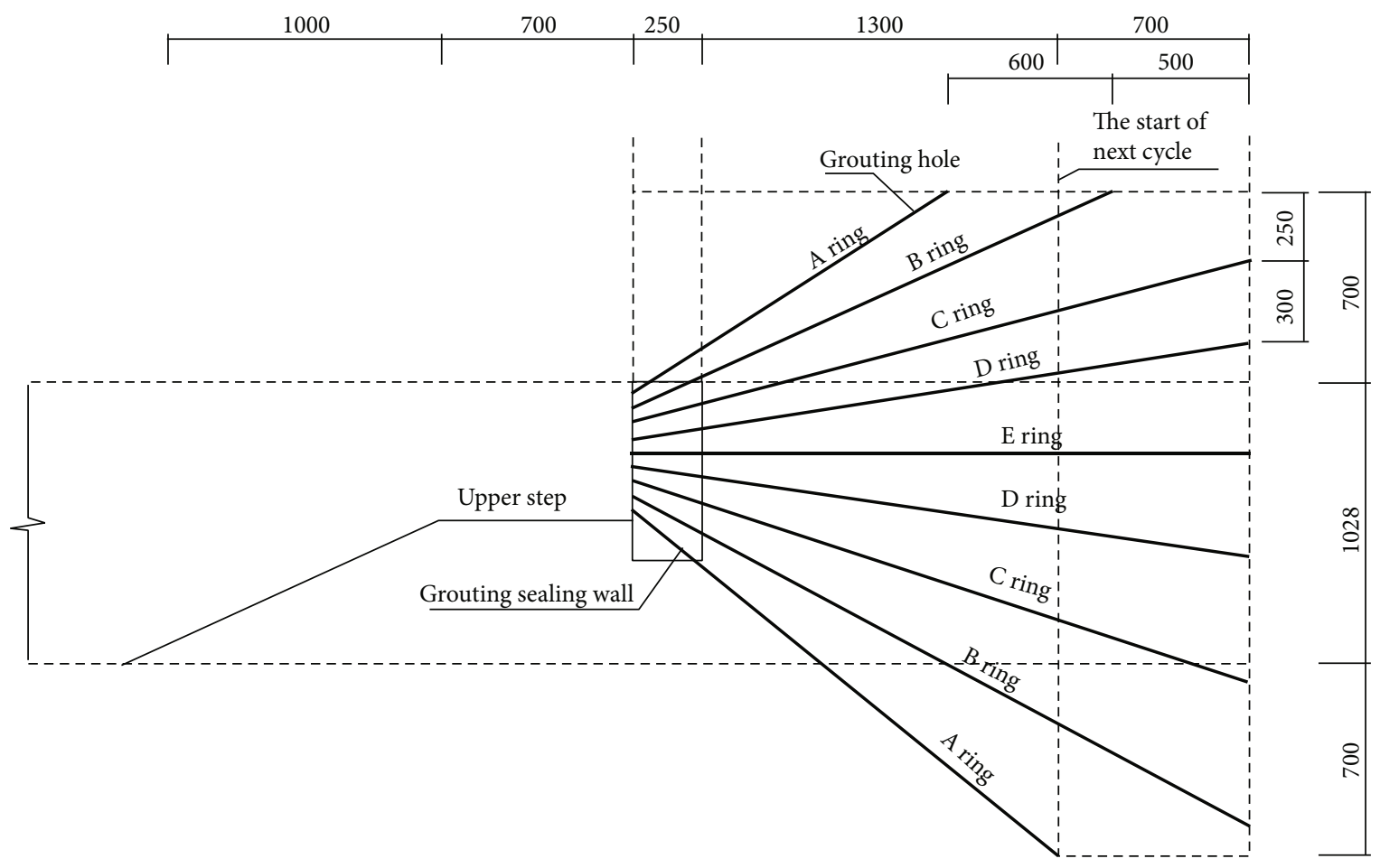

(b)

FIGURE 5: Layout of grouting boreholes: (a) cross section and (b) longitudinal profile.

igneous orientation arrangement. According to the survey data, the rocks are divided into four weathering layers, namely, total weathering, strong weathering, moderate weathering, and breeze weathering, which are mainly composed of variable granitic structure, scaly crystalline structure, and block-shaped and gin-shaped structure.
(1) Complete Weathering Layer. Yellow, brown, and white, extremely soft rock; rock has been weathered into hard plastic sand clay shape; impact drilling can be done; local weathering is not uniform, containing a small amount of highly weathered fragments and quartz sand, distribution discontinuous. 


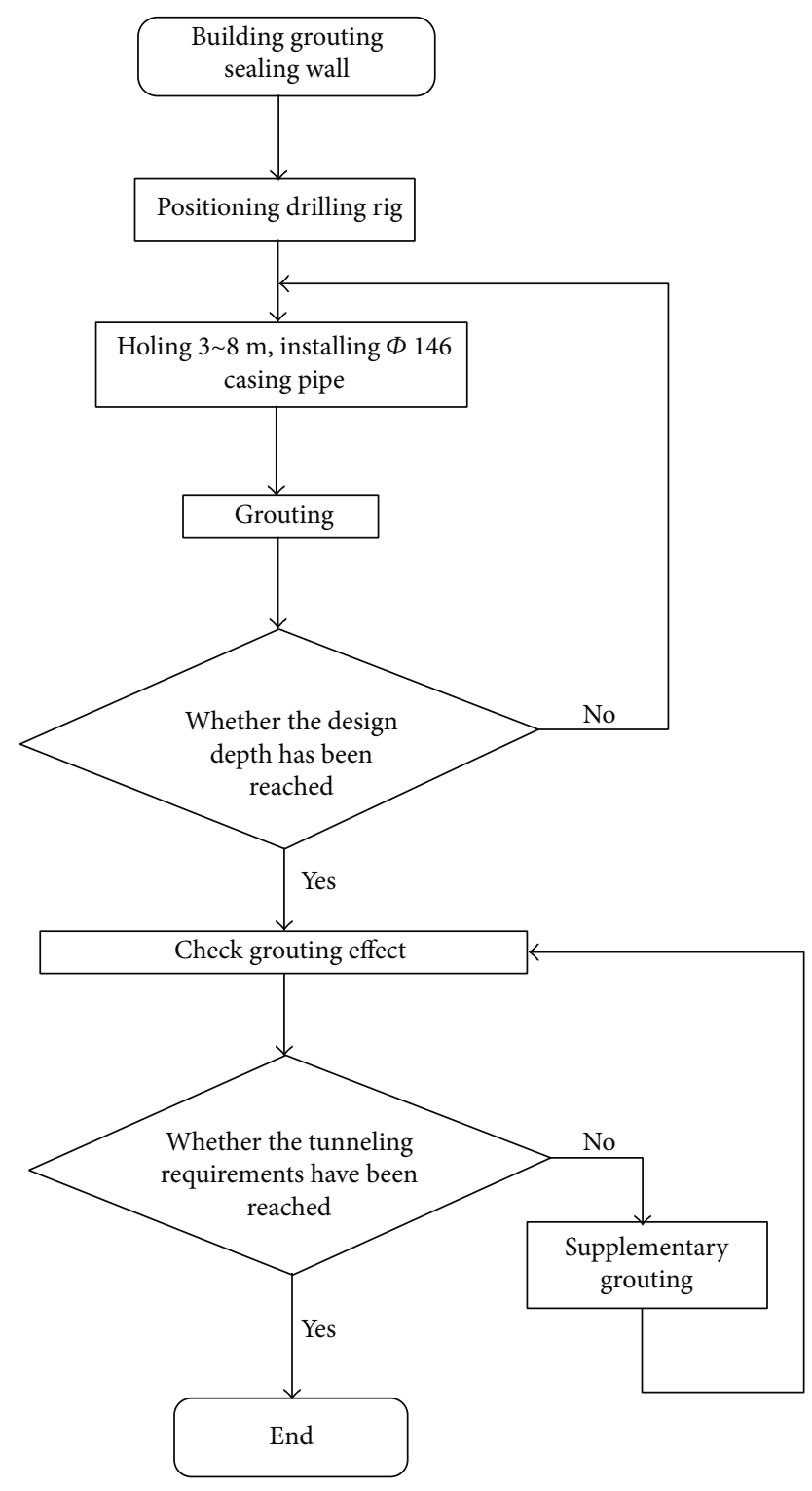

Figure 6: Process of curtain grouting in Junchang tunnel.

(2) Strong Weathering Layer. Gray-yellow, brown-yellow, gray-white, soft to extremely soft rock, fractured to extremely broken rock mass; joints and fissures develop in a network, and fissures are impregnated with iron and manganese. The weathering of this layer is not uniform, and the weathered mixed rock spheroid is embedded locally, and the distribution is discontinuous.

(3) Medium Regolith. Gray, incanus, and taupe, the rock mass changes from relatively hard to hard; the rock mass from relatively broken to complete, the joints and fissures are well developed, and most of the shallow fissures are impregnated with iron and manganese.

(4) Breezy Layer. Gray, taupe, hard rock, relatively complete rock mass, few joints and fractures developed.
2.3. Hydrological Conditions. The groundwater is mainly pore water of loose rock and fissure water of bedrock. The pore water of loose rock belongs to the type of diving, and the fissure water of bedrock belongs to the type of divingconfined water.

There are two sources of pore water replenishment in loose rocks: first, atmospheric rainfall infiltration replenishment is the main replenishment source; the second is the lateral supply of bedrock fissure water. After recharge, groundwater is discharged by means of evaporation, vertical downward seepage to bedrock fissures, or replenishment of surface water, using unconsolidated rock-like pores as runoff channels. This kind of water quantity is limited and unstable, which is affected by season.

There are also two sources of bedrock fissure water supply: first, atmospheric rainfall is the main source of vertically dispersed water supply; the second is the infiltration and recharge of porous water from loose rocks. After receiving the recharge, the bedrock fissure water mainly forms runoff along the tectonic fissure, weathered fissure, and intrusive dike contact zone under the action of water pressure. The runoff condition is obviously controlled by topographic and geomorphic factors and geological structure factors and has the characteristics of short runoff path, large hydraulic slope, and obvious seasonal influence. The bedrock fissure water is mainly percolated vertically; some of which recharge other types of groundwater downward or laterally, and the other part is dispersed and discharged in gully, slope foot, gentle slope and other geomorphic parts in the form of spring water and percolation.

\section{Grouting Treatment Scheme}

3.1. Main Parameters of Full-Face Curtain Grouting. The main parameters of full-section curtain grouting process include grouting curtain length, grouting curtain thickness, grouting borehole layout, types of grouting, grouting method, and grouting stop standard.

3.1.1. Grouting Curtain Length. Because the reinforcing section is mostly soft rocks rich in water, in order to prevent hole collapse and uneven slurry diffusion, the drilling hole is extended according to the average interval of $5 \mathrm{~m}$. Grouting is carried out after each section is completed, and redrilling is carried out after initial setting. The final depth of drilling is $15-25 \mathrm{~m}$ [51]. The length of drilling segment footage and casing should be adjusted according to the breaking of surrounding rock and water inrush during construction. The actual implementation of the drilling process is similar to that shown in Figure 3.

3.1.2. Grouting Curtain Thickness. When the thickness of grouting reinforcement ring is determined, the bearing capacity and project safety of surrounding rock after grouting reinforcement should be considered first, and the project cost and time limit should also be considered. The value is determined mainly through calculation and relevant experience. According to the experience of grouting reinforcement, combined with the engineering, hydrological, and geological 


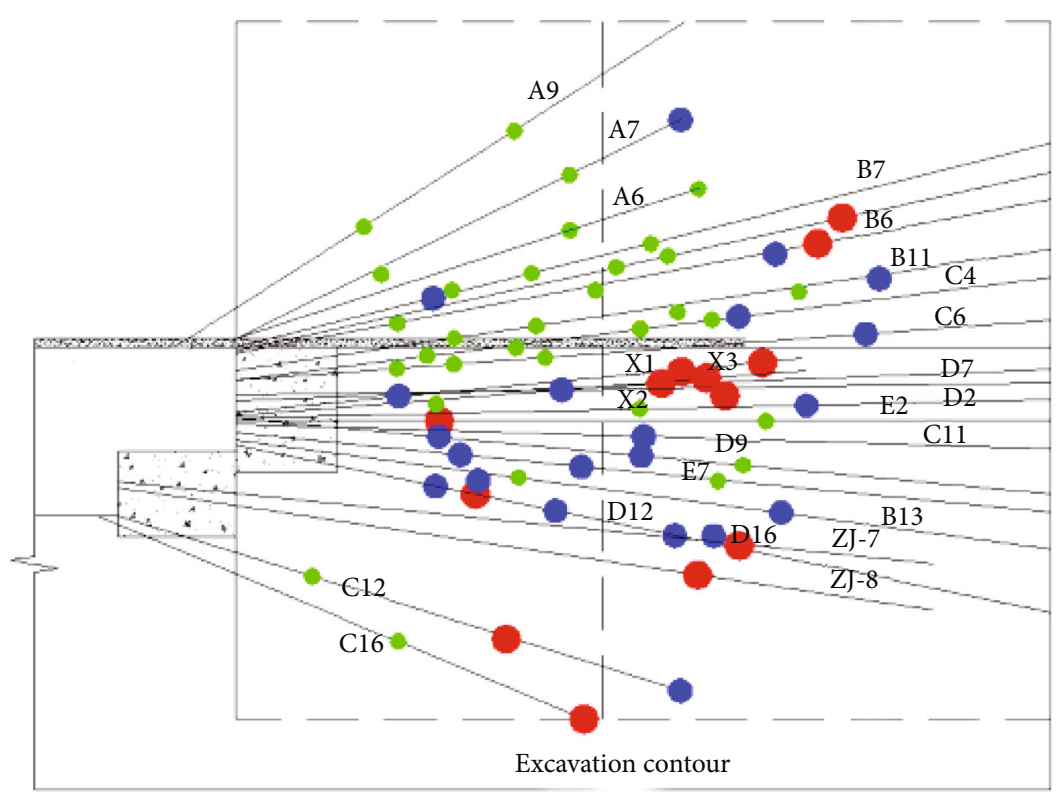

(a)

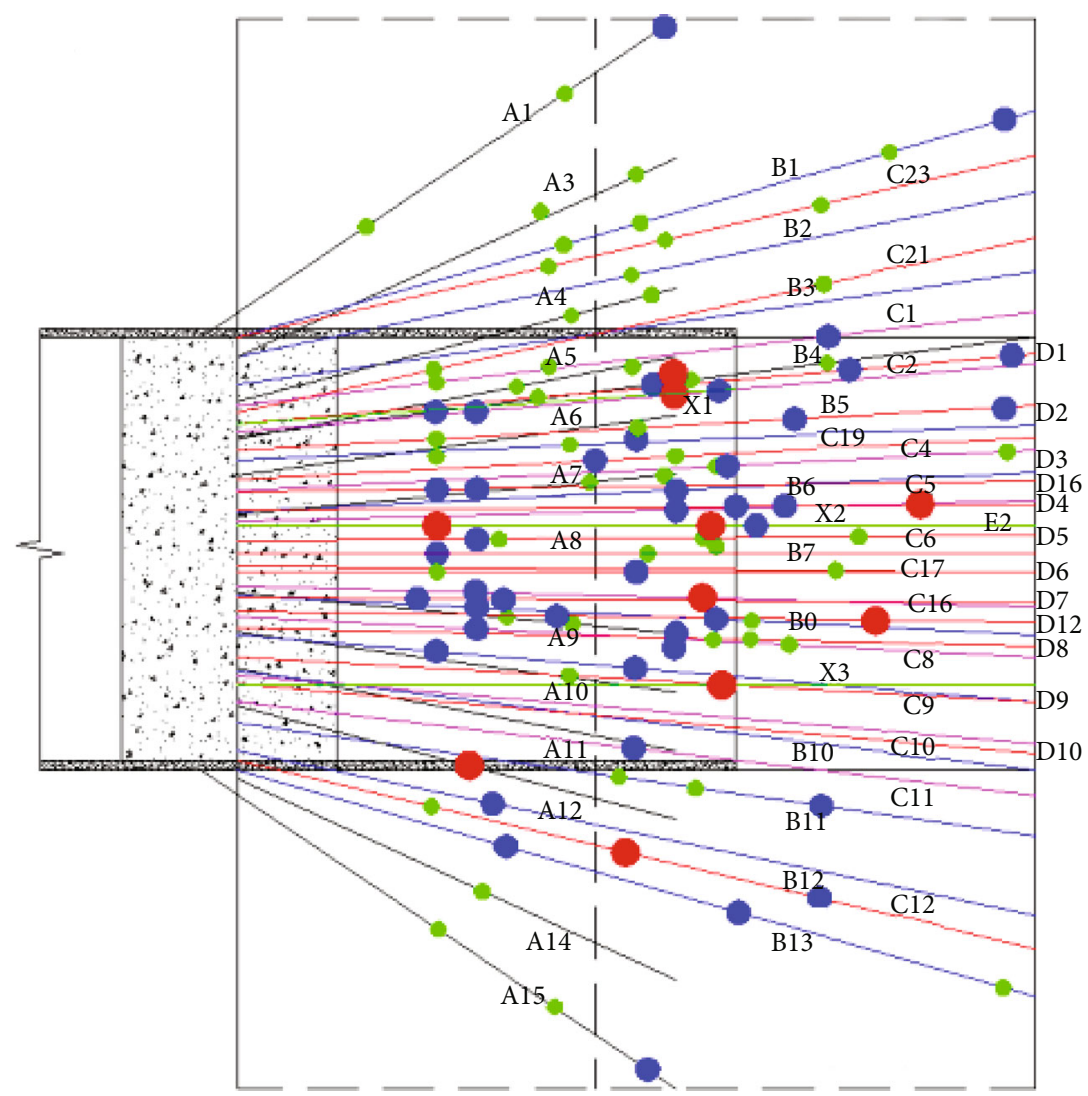

The water inflow is within $3 \mathrm{~L} / \mathrm{min}$

The water inflow is within $3 \mathrm{~L} / \mathrm{min}-10 \mathrm{~L} / \mathrm{min}$

The water inflow is above $10 \mathrm{~L} / \mathrm{min}$

(b)

FiguRE 7: Detection results of some grouting holes: (a) elevation projection and (b) plane projection.

characteristics and the excavated section size of Junchang tunnel, the thickness of grouting curtain in the affected section of the gouge water and mud inrush in Junchang tunnel is $7 \mathrm{~m}$. In the core area of water and mud inrush, the thickness of curtain is appropriately increased to $9 \mathrm{~m}$. The actual thickness of grouting curtain is similar to that in Figure 4. 
TABLE 1: The characteristics of the four detection methods.

\begin{tabular}{|c|c|c|c|c|}
\hline Name & Theory & Operation process & Advantages & Disadva \\
\hline agnetic & $\begin{array}{l}\text { The distribution of groundwater is obtained } \\
\text { by observing the secondary field produced } \\
\text { by the pulse magnetic field }\end{array}$ & $\begin{array}{l}\text { Transmitting pulse magnetic } \\
\text { field-receiving secondary } \\
\text { field }\end{array}$ & $\begin{array}{l}\text { It can reflect the } \\
\text { overall situation of } \\
\text { the front of the face }\end{array}$ & $\begin{array}{l}\text { Easy to be disturbed } \\
\text { by metal goods }\end{array}$ \\
\hline $\begin{array}{l}\text { Water inflow } \\
\text { analysis }\end{array}$ & $\begin{array}{l}\text { The groundwater distribution is obtained } \\
\text { observing the water inflow by drilling }\end{array}$ & Drilling-record & $\begin{array}{l}\text { Direct reflection of } \\
\text { formation water }\end{array}$ & $\begin{array}{l}\text { The } \\
\text { and tl } \\
\text { oc }\end{array}$ \\
\hline $\begin{array}{l}\text { Borehole } \\
\text { investigation }\end{array}$ & $\begin{array}{l}\text { The hole-forming rate of borehole reflects } \\
\text { the integrity and stability of surrounding } \\
\text { rock }\end{array}$ & $\begin{array}{l}\text { Drilling-check } \\
\text { formation of the } \\
\text { record hole form }\end{array}$ & $\begin{array}{l}\text { The operation is } \\
\text { simple and the result } \\
\text { is intuitive }\end{array}$ & $\begin{array}{l}\text { The range } \\
\text { and the res } \\
\text { occasio }\end{array}$ \\
\hline P-Q-T & $\begin{array}{l}\text { The curve of pressure and grouting amount } \\
\text { in grouting test with time reflects the } \\
\text { reinforcement and filling of slurry }\end{array}$ & $\begin{array}{l}\text { Drilling-grouting-record } \\
\text { curve }\end{array}$ & $\begin{array}{l}\text { High accuracy and } \\
\text { accurate prediction }\end{array}$ & Compl \\
\hline
\end{tabular}

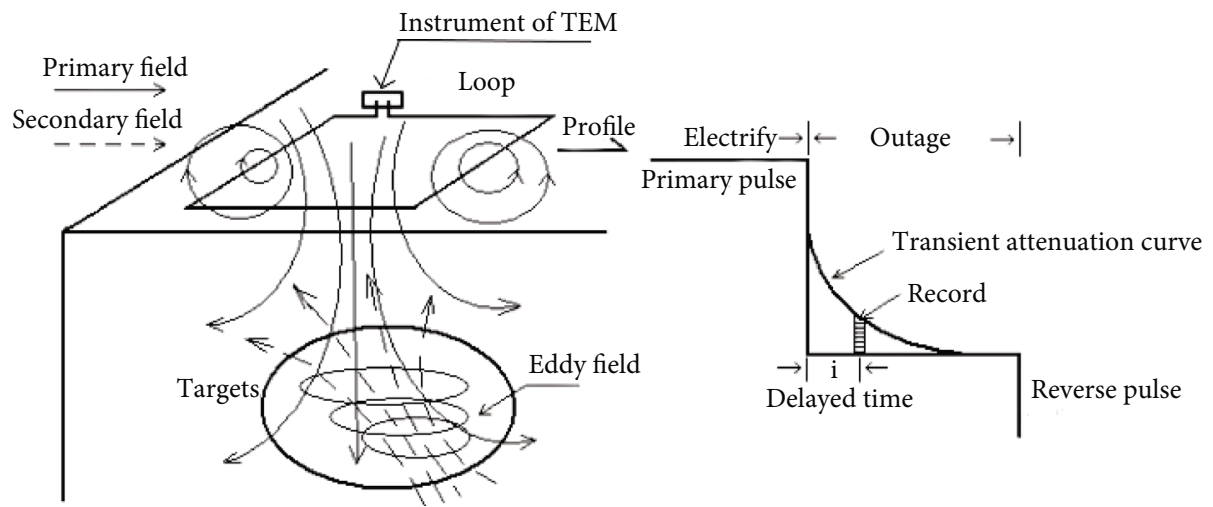

FIgURE 8: The principle of TEM.

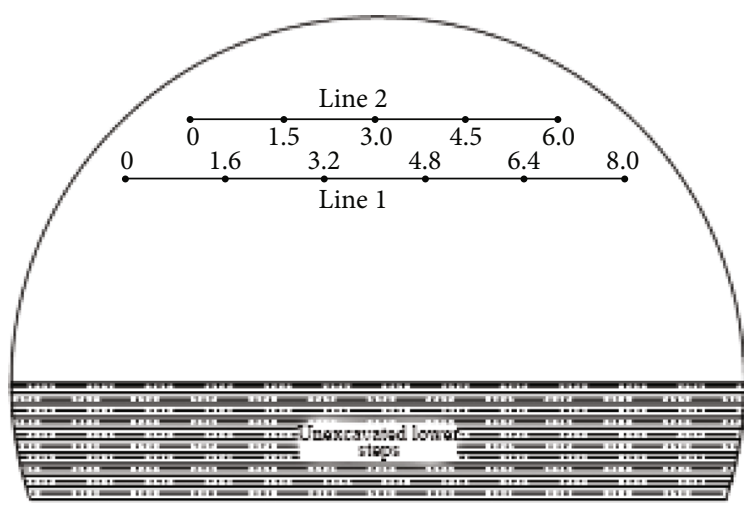

FIGURE 9: Distribution of the survey lines.

3.1.3. Grouting Borehole Layout. In order to ensure the water plugging effect of grouting, five ring grouting holes are arranged according to the required thickness of grouting area and effective penetration length of grouting [52]. Drilling also provides testing. The layout of the grouting boreholes is shown in Figure 5.

3.1.4. Types of Grouting. The raw materials used for curtain grouting include cement, water, and additives, as described below.
(1) Cement. The curtain grouting is made of ordinary Portland cement (P.O. 42.5), the burning loss rate is less than 5\%, the 28-day compressive strength is more than $42.5 \mathrm{MPa}$, the specific surface area is not less than $300 \mathrm{~m}^{2} / \mathrm{kg}$, and the watercement ratio is $0.6: 1 \sim 1: 1$. The concentration of grouting slurry should be changed step by step from dilute to thick. The water cement ratio of grouting slurry can adopt $1: 1$, $0.8: 1$, and $0.6: 1$. The water-cement ratio at the beginning of grouting can be $1: 1$.

(2) Cement-Sodium Silicate. The concentration of sodium silicate is $35^{\circ} \mathrm{Be}$, the modulus is controlled between 2.3 and 3.0, the volume ratio of cement slurry and sodium silicate is $1: 1 \sim 5: 1$, and the gelation time is $40 \mathrm{~s} \sim 60 \mathrm{~s}$.

(3) Hongyu-1. Hongyu-1 (Hy-1) is a clay cement paste with early strength and erosion resistance, which is composed of sodium metaluminate, soluble sodium metasilicate powder, aluminum sulfate, polyacrylamide, hydroxyethyl cellulose, sodium hashed phosphate, and main material BS. The volume ratio of cement slurry and Hongyu No. 1 during grouting is $1: 1 \sim 5: 1$, and the cementation time is within $30 \mathrm{~s} \sim 15 \mathrm{~min}$. The fluidity is reduced to $60 \mathrm{~mm} \sim 130 \mathrm{~mm}$ within $3 \mathrm{~min}$, the unconfined compressive strength can reach $0.2 \mathrm{MPa}$ after 2 hours, exceeding $0.6 \mathrm{MPa}$ after 1 day, the unconfined compressive strength can reach $0.8 \mathrm{MPa} \sim 15 \mathrm{MPa}$ 


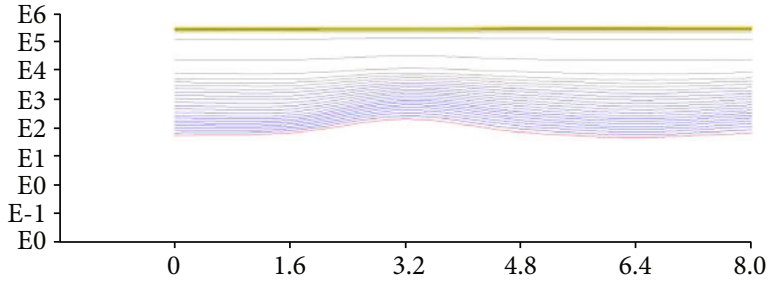

(a)

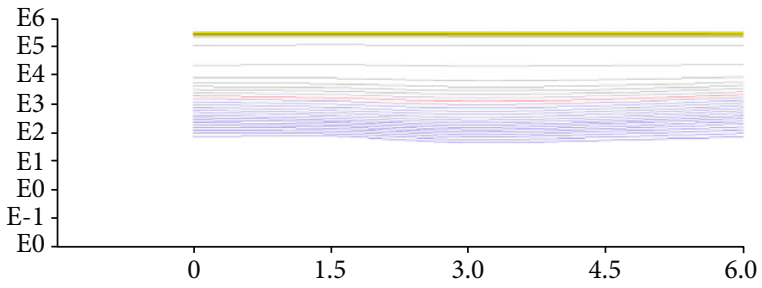

(b)

FIGURE 10: Graph of induced electromotive force: (a) line 1 and (b) line 2.

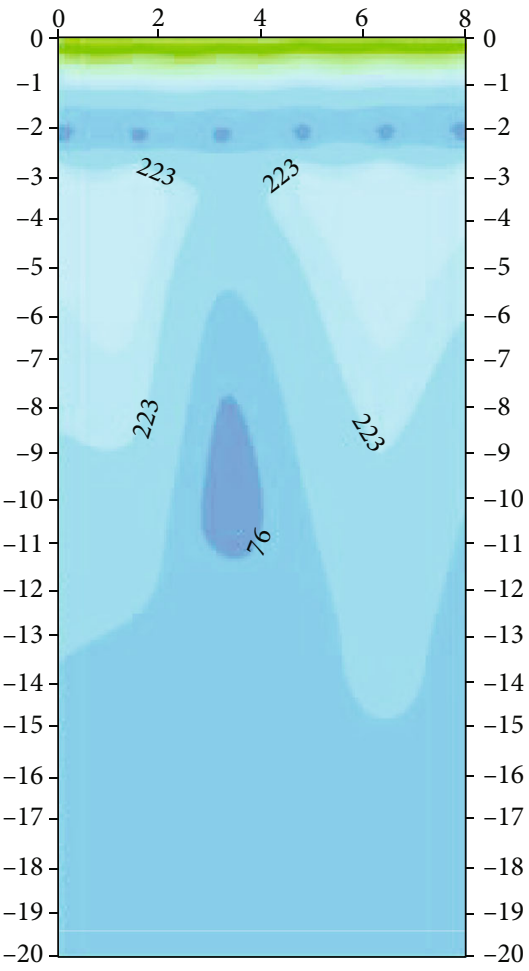

(a)

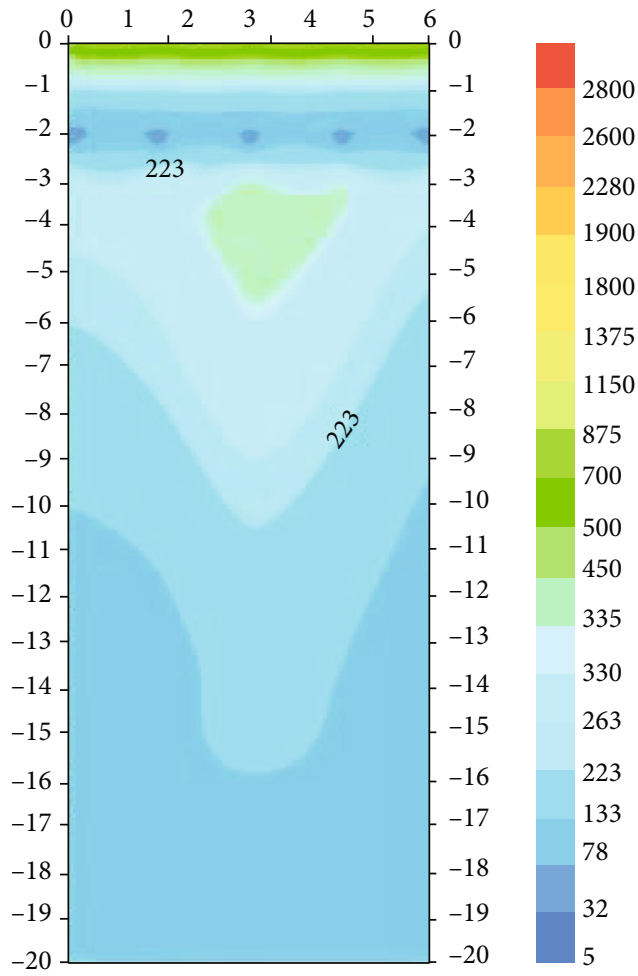

(b)

FIGURE 11: Resistivity isoline: (a) line 1 and (b) line 2.

after 28 days, and the impermeability coefficient is within the range of $6 \times 10^{-8} \sim 8 \times 10^{-8} \mathrm{~cm} / \mathrm{s}$.

(4) Acidic Sodium Silicate. Acid sodium silicate takes sulfuric acid and sodium silicate as the main raw materials, it is not restricted by acid-base formation, and permeability is good. Sulfuric acid is diluted from $98 \%$ concentrated sulfuric acid to $10 \%$ dilute sulfuric acid. The volume ratio of sodium silicate and dilute sulfuric acid is $3: 1 \sim 1: 1$.

The type of grout used for grouting shall be determined according to the amount of water produced during drilling. When the drilling water output is small medium flow rate (or small flow rate), that is, when the water output is less than $0.18 \mathrm{~L} /(\mathrm{min} \cdot \mathrm{m})$, the grouting slurry mainly consists of cement slurry or cement sodium silicate. When the drilling water output is between $0.18 \mathrm{~L} /(\mathrm{min} \cdot \mathrm{m})$ and $0.9 \mathrm{~L} /(\mathrm{min} \cdot \mathrm{m})$, the slurry is mainly Hy-1 or cement sodium silicate. When the output of borehole is greater than $0.9 \mathrm{~L} /(\mathrm{min} \cdot \mathrm{m})$, the slurry is mainly Hy-1. Acidic sodium silicate should be used if normal slurry is difficult to penetrate.

3.1.5. Grouting Method. In order to prevent the uneven diffusion of slurry in the crushed surrounding rock, progressive piecewise grouting process is adopted, that is, from shallow to deep, reinforced section by section and advanced layer by layer. The average piecewise grouting length is $5 \mathrm{~m}$, which is appropriately increased to $8.0 \mathrm{~m}$ in the area with relatively complete rock and no water. Reduce the grouting interval to $3.0 \mathrm{~m}$ in case of water enrichment, loose crushing, etc. Alternate drilling and injection during construction, and use orifice pipe to prevent slurry from flowing out.

3.1.6. Grouting Stop Standard. The completion standard of grouting adopts the combination of grouting amount and pressure, which is controlled mainly by the way of pressure. 


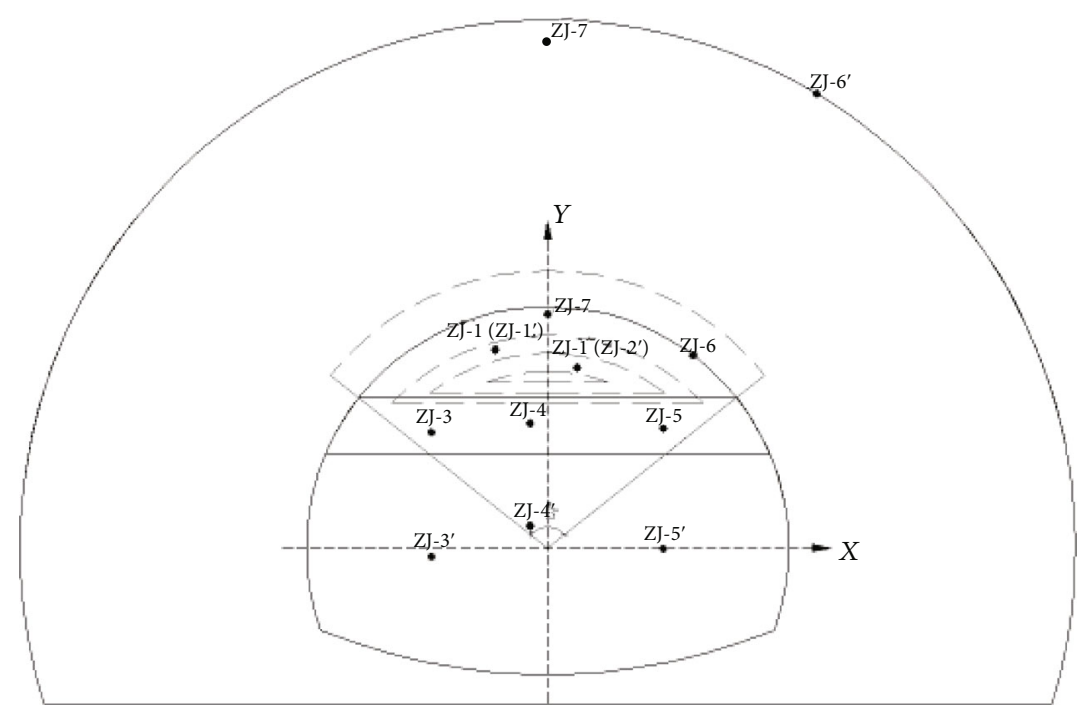

(a)

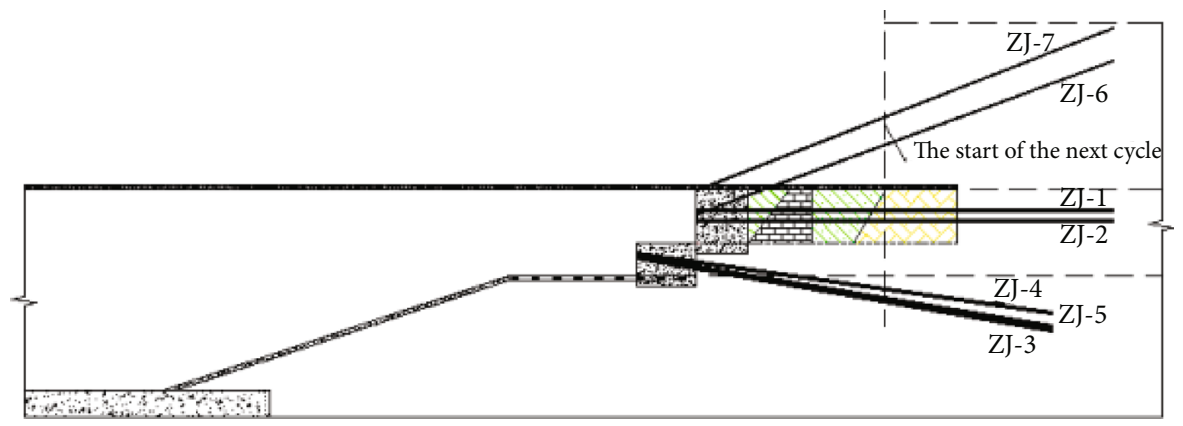

(b)

FIGURE 12: Layout of detection hole: (a) cross section and (b) longitudinal profile. ZJ1 ZJ6 in the figure is the opening position of the inspection hole, and $\mathrm{ZJ} 1^{\prime} \sim \mathrm{ZJ} 6^{\prime}$ is the final hole position.

TABLE 2: Test results of water inflow through the hole.

\begin{tabular}{|c|c|c|c|c|c|c|}
\hline Number & $\begin{array}{l}\text { Depth of } \\
\text { the hole } \\
(\mathrm{m})\end{array}$ & $\begin{array}{l}\text { Depth at which the } \\
\text { water starts gushing } \\
(\mathrm{m})\end{array}$ & $\begin{array}{c}\text { Initial water } \\
\text { inflow }(\mathrm{L} / \mathrm{min})\end{array}$ & $\begin{array}{c}\text { Initial water flow per } \\
\text { extension meter } \\
(\mathrm{L} /(\mathrm{min} \cdot \mathrm{m}))\end{array}$ & $\begin{array}{c}\text { Steady water } \\
\text { inflow }(\mathrm{L} / \mathrm{min})\end{array}$ & $\begin{array}{c}\text { Steady water flow per } \\
\text { extension meter } \\
(\mathrm{L} /(\mathrm{min} \cdot \mathrm{m}))\end{array}$ \\
\hline $\mathrm{ZJ}-1$ & 21 & No & No water & No water & No water & No water \\
\hline ZJ-2 & 21 & No & No water & No water & No water & No water \\
\hline $\mathrm{ZJ}-3$ & 20 & 15 & 30 & 1.5 & 25 & 1.25 \\
\hline ZJ-4 & 20 & 15 & 30 & 1.5 & 25 & 1.25 \\
\hline ZJ-5 & 20 & 15 & 15 & 0.75 & 10 & 0.5 \\
\hline ZJ-6 & 21 & 18 & 2 & 0.1 & 1 & 0.05 \\
\hline ZJ-7 & 21 & 16 & 8 & 0.13 & 5 & 0.24 \\
\hline
\end{tabular}

When the grouting pressure reaches the design final pressure and the grouting amount reaches more than $80 \%$ of the design grouting amount, the grouting is finished.

3.2. Process of Full-Face Curtain Grouting. The main program of curtain grouting is shown in Figure 6. First of all, the grouting sealing wall is built to resist the high grouting pressure, thus protecting the operator and the machine. After the curing period of the concrete of the grouting sealing wall, the grouting hole location is determined according to the design scheme. Then, position the rig to install the borehole orifice tube. After the preparation work is completed, the drilling begins. Under the first segment length is $3 \sim 8 \mathrm{~m}, \Phi$ $146 \mathrm{~mm}$ casing pipe, the casing pipe external use cementsodium silicate slurry seal, for the first time grouting. After the initial setting, the drilling is carried out again, and the depth is extended according to the average $5 \mathrm{~m}$ until the design depth is reached. After grouting, Transient Electromagnetic Methods, water inflow analysis, borehole investigation, and $\mathrm{P}-\mathrm{Q}-\mathrm{T}$ method are used to test the grouting effect. If 


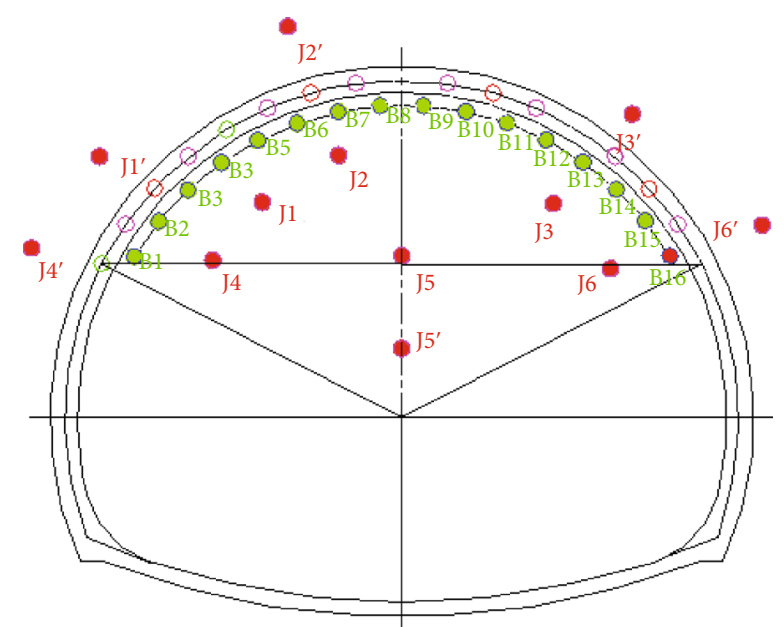

FIGURE 13: Layout of detection hole. J1 J6 in the figure is the opening position of the inspection hole, and $\mathrm{J} 1^{\prime} \sim \mathrm{J} 6^{\prime}$ is the final hole position.

TABLE 3: Completion rate of boreholes.

\begin{tabular}{lccc}
\hline Number & $\begin{array}{c}\text { Depth of the } \\
\text { hole }(\mathrm{m})\end{array}$ & $\begin{array}{c}\text { Initial hole } \\
\text { depth }(\mathrm{m})\end{array}$ & $\begin{array}{c}\text { Initial completion rate of } \\
\text { boreholes }(\%)\end{array}$ \\
\hline J1 & 17 & 17 & 100 \\
J2 & 12 & 12 & 100 \\
J3 & 15 & 14 & 93.3 \\
J5 & 15 & 15 & 100 \\
J6 & 15 & 15 & 100 \\
\hline
\end{tabular}

the grouting work meets the design requirements, the tunnel will continue to tunneling. Conversely, if the requirements are not met, supplementary grouting is carried out.

In the grouting process, in order to reduce the impact of grouting on the initial support, the cavity of the original initial support part is filled with grouting first. At the same time, in order to reduce the difficulty of later excavation, low pressure and thick slurry are used for filling grouting. Then, according to the distribution of boreholes, each ring drilling is divided into three sequence construction, grouting sequence according to the distribution of boreholes, from the bottom to the top, from both sides to the middle construction. In the process of grouting, if the grouting pressure is low in the early stage of grouting, the main goal is to increase the slurry diffusion range, and the grouting amount can be increased appropriately. When the scope of slurry reinforcement nearly meets the requirements of grouting end, the grouting pressure is taken as the control index. In order to reduce the grouting cost, when the slurry diffusion distance is far beyond the design range after analysis or when the grouting pressure does not rise for a long time, the watercement ratio of slurry should be adjusted to shorten the gelation time, and intermittent grouting should be adopted to control the slurry diffusion range.

3.3. Construction of Full Full-Face Curtain Grouting. Grouting construction adopts the principle of "combination of exploration and injection," and the drilling at the beginning of each cycle should undertake the task of construction investigation at the same time. Specifically, the previous series of holes should be used as exploration holes to master the properties of surrounding rocks and hydrogeological conditions of the area that need to be governed, so as to provide basis for subsequent hole construction. According to the investigation, the type of grout, water-cement ratio, pressure, etc. are selected for grouting, and the key reinforcement areas of curtain grouting are constantly modified and determined.

The latter sequence of grouting holes is also used to check the grouting effect of the front sequence holes and to timely understand the grouting effect of the previous period (diffusion direction, range, filling degree, consolidation strength of the stone body, etc.), so as to optimize the grouting method. For the area with good grouting effect in the early stage, grouting can be reduced appropriately in the later stage. On the contrary, for the area with weak grouting effect in the previous period, the grouting amount can be increased appropriately. The detection results of some grouting holes are shown in Figure 7.

3.4. Evaluation of Grouting Effect. After the grouting is completed, in order to verify the grouting effect and ensure the grouting quality, the grouting effect shall be tested. The grouting effect was tested by Transient Electromagnetic Methods, water inflow analysis, borehole investigation, and P-Q-T method. These four methods have their own characteristics, and the reliability of detection is improved by using them together. Their characteristics are shown in Table 1.

3.4.1. Transient Electromagnetic Methods. Transient Electromagnetic Methods (TEM) are a method to send a primary pulse magnetic field to the ground by ungrounded loop or ground source and to observe the secondary eddy current field by coil or ground electrode during the interval of the primary pulse magnetic field. Its mathematical and physical basis is the problem of eddy current field caused by magnetic field excited by step change of conductive medium. The working principle is as follows. Through the coil laid on the ground, a pulsed magnetic field (primary field) is sent to the underground. Under the action of the primary field, the underground medium will produce an eddy field. When the pulsed magnetic field disappears, the eddy does not disappear synchronously, but has a slow attenuation process. By observing and studying the variation law of the secondary magnetic field generated by the eddy current attenuation process with time on the surface, the vertical variation of the earth potential can be detected to understand the electrical distribution of the underground media. The property of transient electromagnetic field constitutes the basic principle for TEM to distinguish different geological bodies under suitable conditions. The principle of TEM is shown in Figure 8.

After the completion of grouting in this project, two survey lines are arranged in the tunnel to test the grouting effect. The survey line layout is shown in Figure 9. The effect of grouting is reflected by induction electromotive force curve and resistivity isoline. The detection results are shown in Figures 10 and 11. 
J1 hole
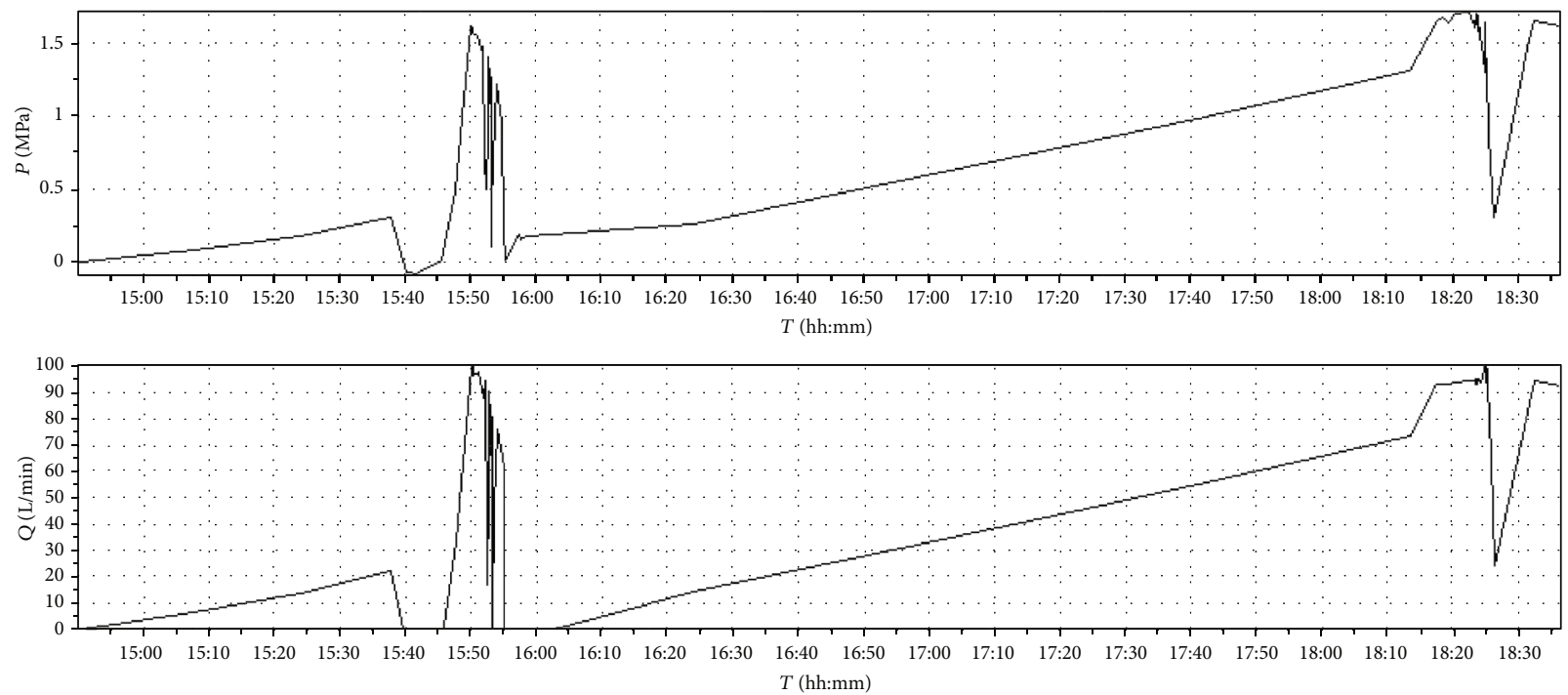

Figure 14: P-Q-T curve of hole J1.
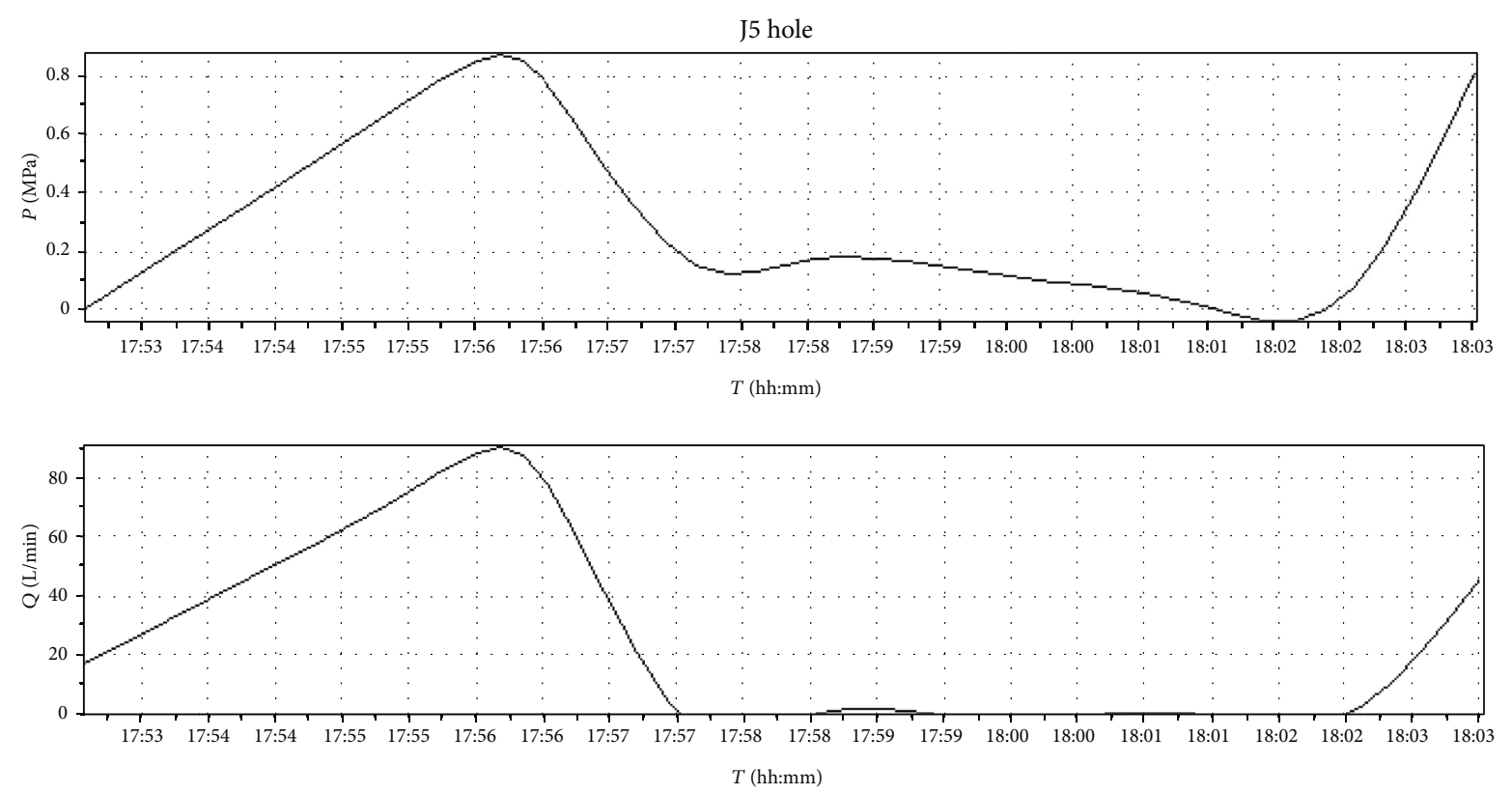

FIgURe 15: P-Q-T curve of hole J5.

The analysis of the detection results in Figure 10 shows that the late induced electromotive force at $3.2 \mathrm{~m}$ of survey line 1 is obviously higher than other measuring points of the same survey line, indicating that there is an abnormal low resistance relative to other measuring points, which may contain groundwater. The late induced electromotive force of the whole line of survey line 2 is not significantly different, and there is no abnormality relative to other survey points in this line.

As can be seen from Figure 10, the overall measured resistivity is low. The area within $6 \mathrm{~m}$ ahead of the palm after survey line 1 and within $8 \mathrm{~m}$ ahead of the palm after survey line 2 has relatively high resistivity, so it is speculated that the area contains water. The area beyond $6 \mathrm{~m}$ ahead of the palm after survey line 1 and beyond $8 \mathrm{~m}$ ahead of the palm after survey line 2 shows unusually low resistance. It is speculated that the area still contains a lot of groundwater.

3.4.2. Water Inflow Analysis. Most of the grouting area in this circulation section is water-rich stratum, which is composed of completely and strongly weathered granite and weathered quartz sand, which has important reference significance for subsequent tunnel excavation. Therefore, it is necessary to 


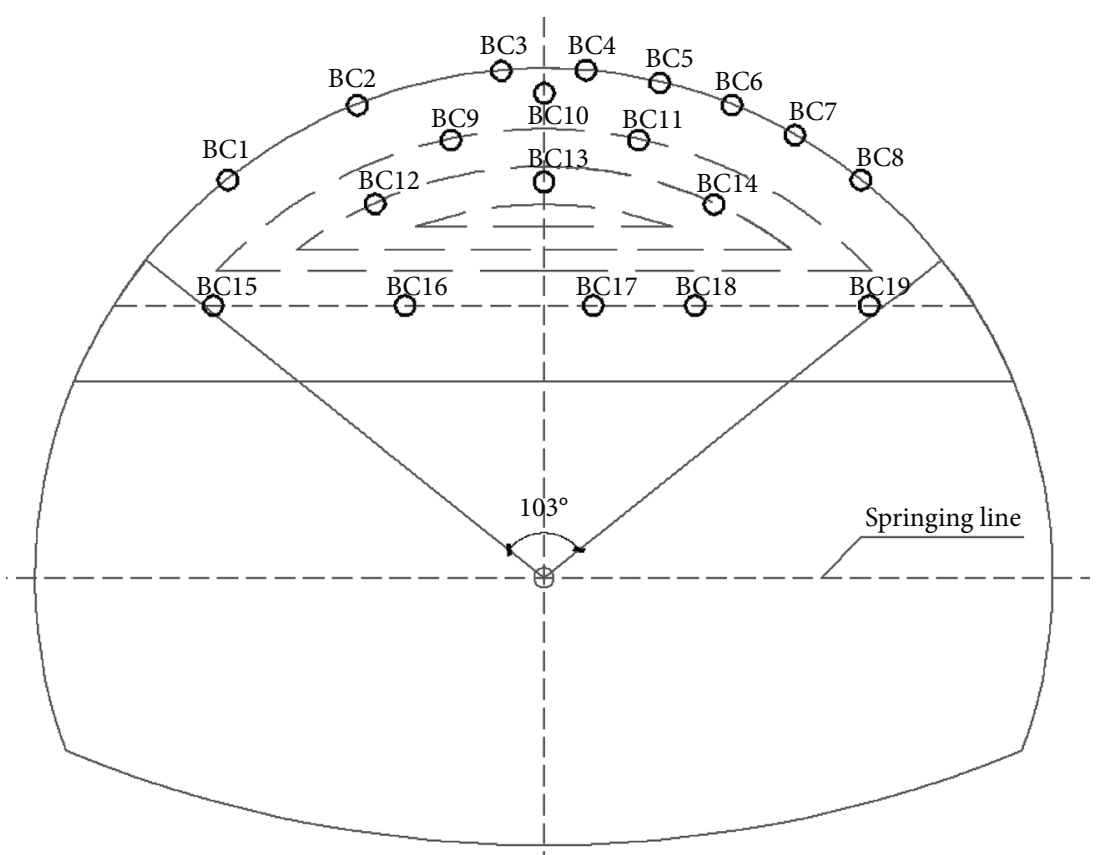

(a)

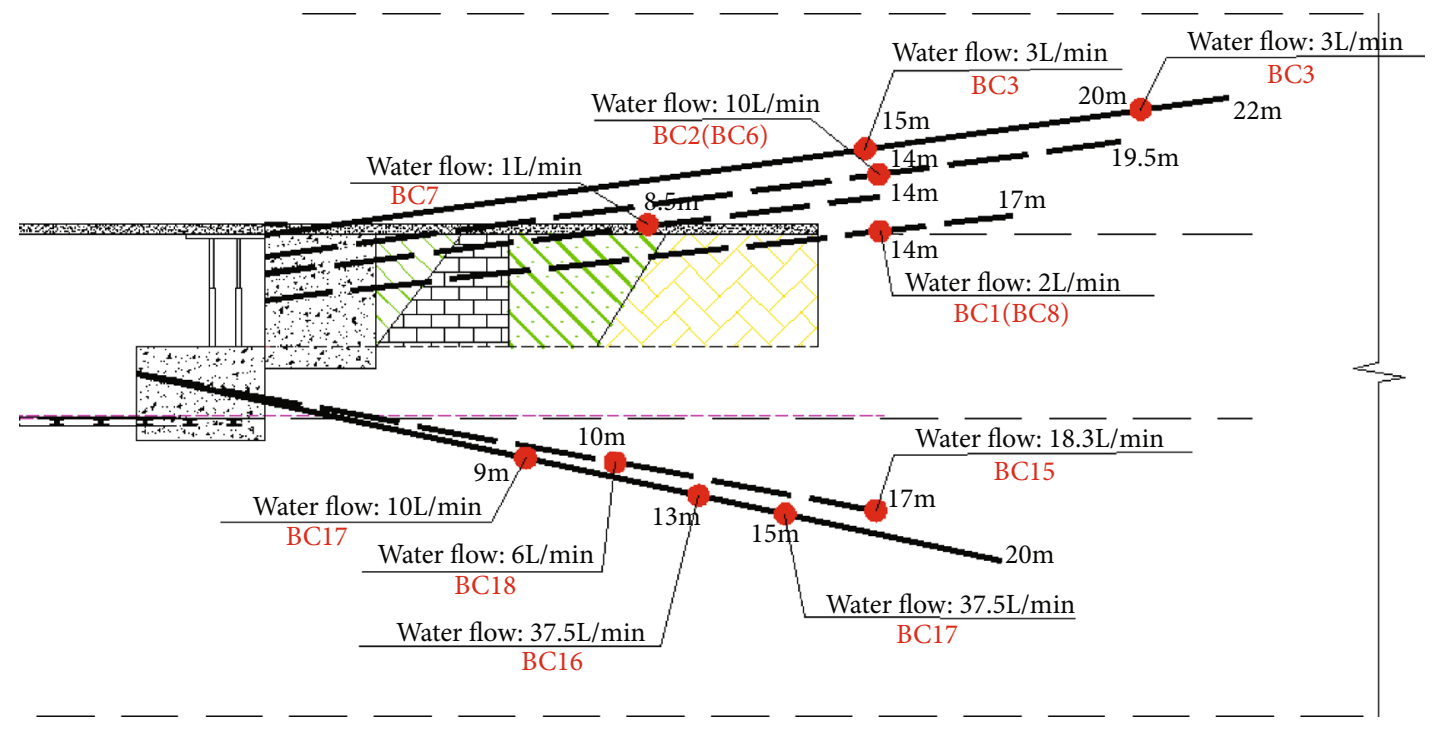

(b)

FIGURE 16: Drilling results of supplementary grouting. (a) Borehole layout in cross section. (b) Borehole layout in longitudinal profile and water gushing condition of some holes.

set up more inspection holes to evaluate the effect of grouting reinforcement. In consideration of the difficulty of construction, the number of inspection holes is set to 7 . The layout of detection holes is shown in Figure 12.

The water inflow test results are shown in Table 2. It can be seen that the water output of ZJ-1, ZJ-2, and ZJ-6 self-test holes is significantly lower than that before grouting, which proves that grouting plugging is effective, but the water output of ZJ-3, ZJ-4, ZJ-5, and ZJ-7 is still large. In addition, it is found after drilling $14-16 \mathrm{~m}$ that there is a large amount of water in the arch roof and mud is gushing during drilling, indicating that the water passage is not completely closed and the groundwater under the upper and lower steps still have a strong hydraulic connection. The test results show that the water content in the tunnel decreases, but the grouting is still insufficient to meet the requirements of further tunneling, so the grouting effect needs to be further improved.

3.4.3. Borehole Investigation. Six inspection holes were arranged, and the layout of opening and final holes is shown in Figure 13. After the drilling is completed and the drill pipe is withdrawn, fine steel tubes are used to detect the formation of holes, of which J4 hole is not drilled and the formation of holes in the inspection hole is shown in Table 3. As can be seen from the table, the completion rate of boreholes is more than $90 \%$. The results show that full-section curtain grouting 


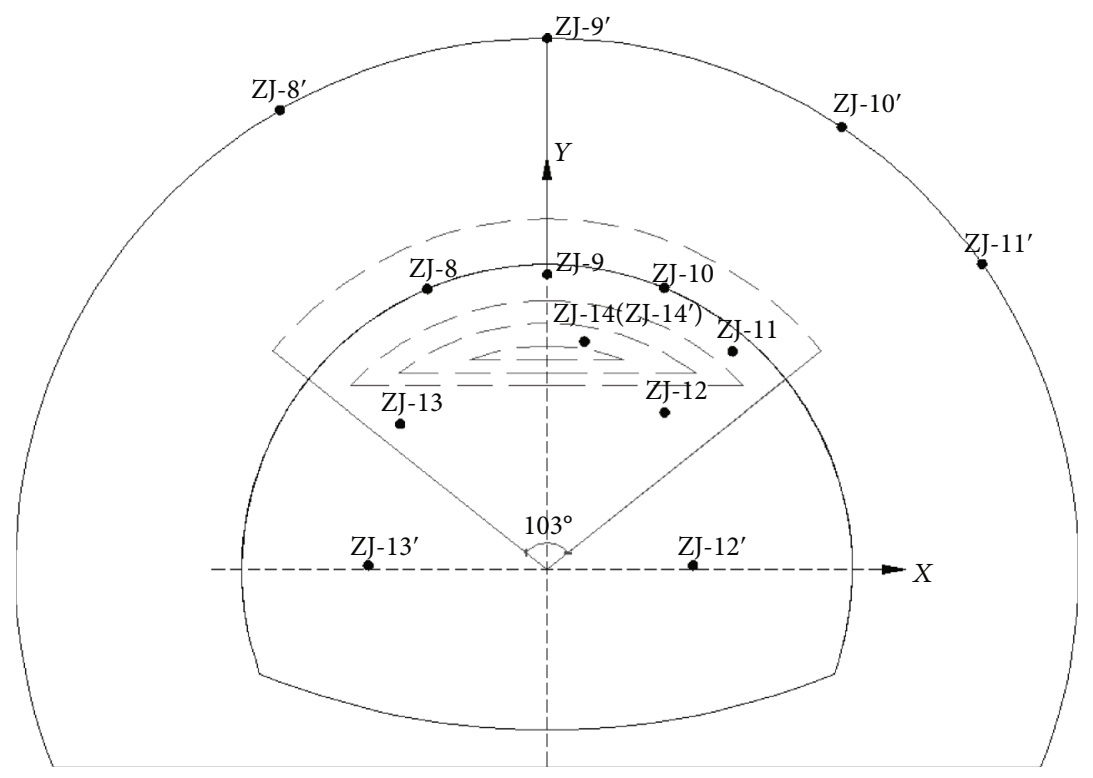

(a)

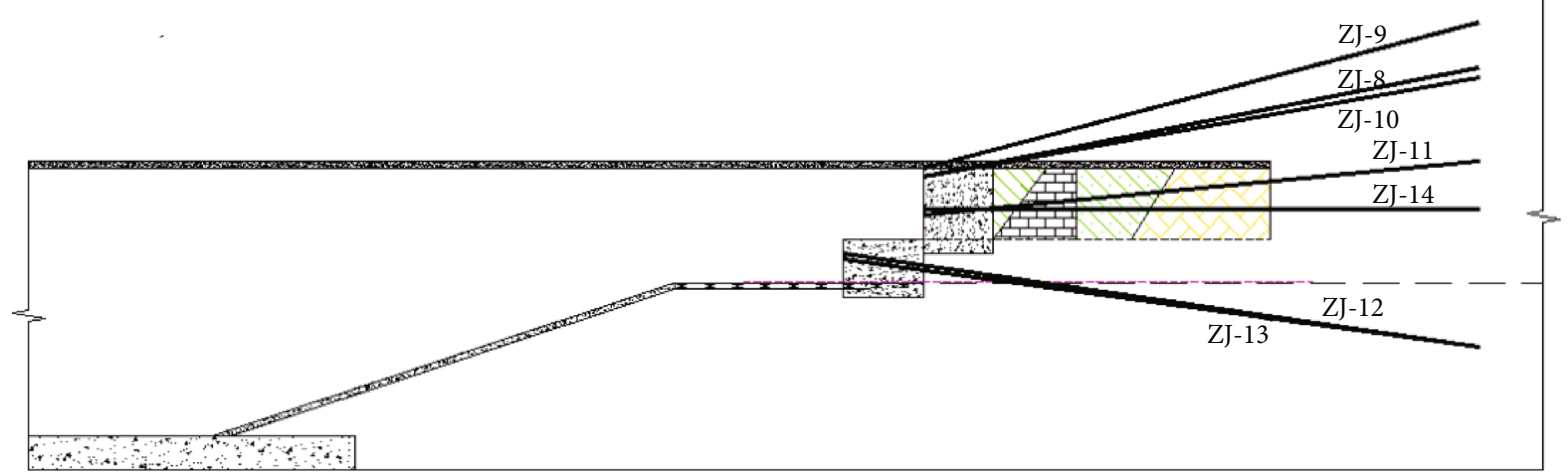

(b)

Figure 17: Layout of detection hole after supplementary grouting: (a) cross section and (b) longitudinal profile.

can significantly improve the stability of surrounding soil and is beneficial to tunnel excavation.

3.4.4. P-Q-T Method. The grouting test is carried out on the borehole of the borehole investigation method, and the curtain grouting effect is judged according to the P-Q-T curve characteristics of the inspection hole. Cement slurry is used for grouting.

(1) For Hole J1. The hole forming depth is $17 \mathrm{~m}$, and the grouting pressure increases slowly after the grouting begins. During this period, the grout oozes from hole J2, and then, the grouting is done after it is sealed. The maximum grouting pressure is $1.6 \mathrm{MPa}$. The grouting test is stopped due to the emergence of slurry leakage in the vault. During the period, the grouting flow also fluctuates with the change of grouting pressure. The P-Q-T curve in the grouting process is shown in Figure 14.

(2) For Hole J5. For the J5 inspection hole, the grouting pressure slowly increases to $0.9 \mathrm{MPa}$ after the grouting begins, and then, the grouting pressure drops rapidly due to the cracks in the bottom grouting sealing wall. In the later stage, the grouting is stopped due to the large amount of slurry penetration in the grouting sealing wall. The P-Q-T curve of grouting process is shown in Figure 15.

(3) For Other Holes. The remaining inspection holes have not been inspected due to the serious leakage of cement from other locations during grouting.

In the grouting $\mathrm{P}-\mathrm{Q}-\mathrm{T}$ curve results of these holes, the pressure increases slowly. The pressure of $\mathrm{J} 1$ hole reaches $1.5 \mathrm{MPa}$ within $10 \mathrm{~min}$ and that of $\mathrm{J} 5$ hole rises to $0.9 \mathrm{MPa}$ within $5 \mathrm{~min}$. However, due to the serious slurry leakage in other holes, grouting wall, and arch rock mass, the pressure drops quickly and grouting is stopped in the later period. Therefore, the inspection hole $\mathrm{P}-\mathrm{Q}-\mathrm{T}$ curve is not perfect.

3.5. Supplementary Grouting. The results of various detection methods show that through full-section curtain grouting the 

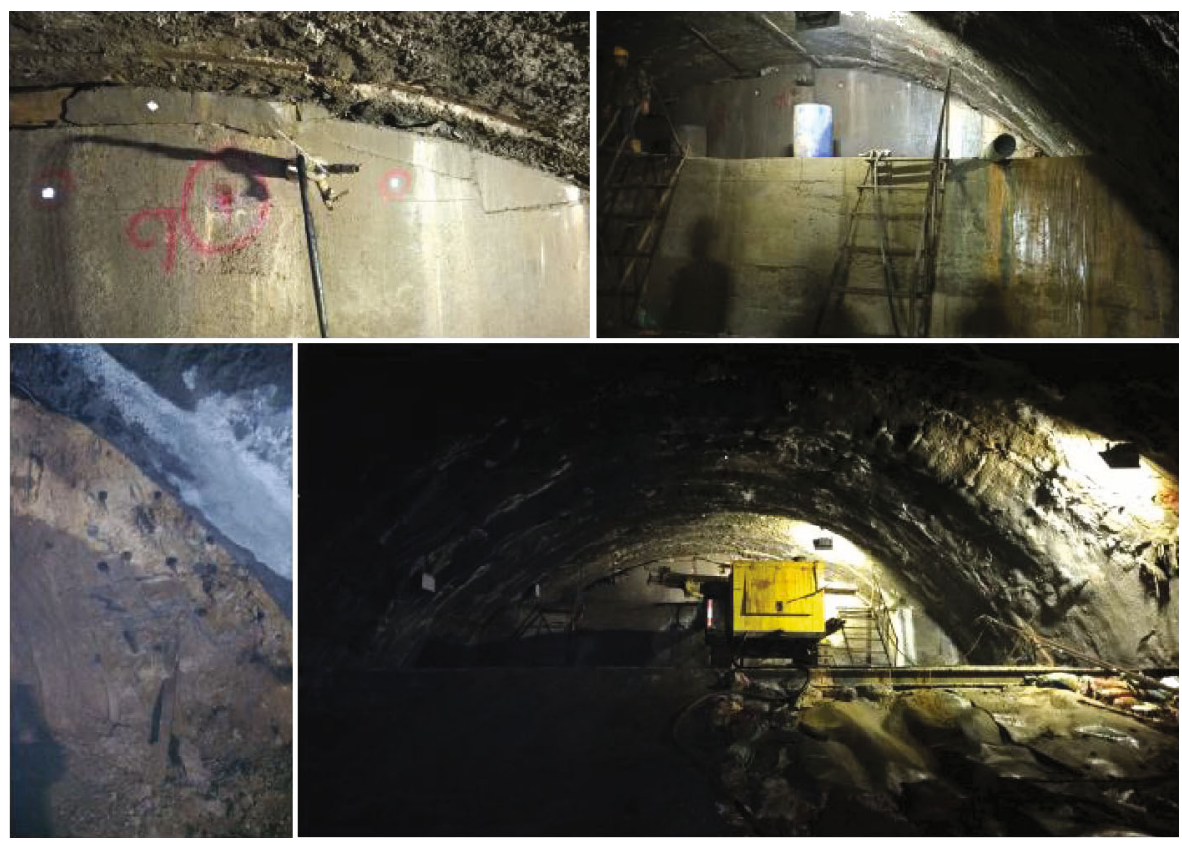

FIgURE 18: The situation after grouting.

TABLE 4: Test results of supplementary grouting.

\begin{tabular}{|c|c|c|c|}
\hline Number & Geological conditions & Water gushing condition & Hole formation rate \\
\hline ZJ-8 & $\begin{array}{l}0-8 \mathrm{~m} \text { is dry soil, and } 8-14 \mathrm{~m} \text { is } \\
\text { highly weathered rock. }\end{array}$ & $\begin{array}{l}\text { When the drilling is completed, no water will } \\
\text { flow out. After the drilling is completed, clear water } \\
\text { flow out in } 10 \text { minutes. The water flow is } 6 \mathrm{~L} / \mathrm{min} \text {. }\end{array}$ & $85 \%$ \\
\hline ZJ-9 & $0-15 \mathrm{~m}$ is dry soil, and $15-20 \mathrm{~m}$ is wet soil. & $\begin{array}{c}\text { Flowing water starts from } 20 \mathrm{~m} \text {, and the flow is } 2.1 \mathrm{~L} / \mathrm{min} \\
\text { and the water quality is clear. }\end{array}$ & $100 \%$ \\
\hline ZJ-10 & $0-12 \mathrm{~m}$ is strongly weathered granite. & $\begin{array}{l}\text { Yellow mud flows out at } 12-20 \mathrm{~m} \text {, and the flow is } \\
1.8 \mathrm{~L} / \mathrm{min} \text {. The water quality is clear after drilling. }\end{array}$ & $100 \%$ \\
\hline ZJ-11 & $1-15 \mathrm{~m}$ is dry soil, and $15-20 \mathrm{~m}$ is wet soil. & $\begin{array}{l}\text { Yellow mud flows out at } 12-20 \mathrm{~m} \text {, and the } \\
\text { flow is } 6 \mathrm{~L} / \mathrm{min} \text {. }\end{array}$ & $100 \%$ \\
\hline ZJ-12 & $\begin{array}{l}1-9 \mathrm{~m} \text { is the weathered rock, and } 9-13 \mathrm{~m} \text { is } \\
\text { the strongly weathered rock, which is plastic. }\end{array}$ & $\begin{array}{l}\text { Yellow mud flows out at } 13-20 \mathrm{~m} \text {. Water } \\
\text { starts to flow out at } 18 \mathrm{~m} \text {, and the water flow is } \\
2.2 \mathrm{~L} / \mathrm{min} \text {. The water quality is yellow mud water. }\end{array}$ & $100 \%$ \\
\hline ZJ-13 & $\begin{array}{l}0-5 \mathrm{~m} \text { is dry soil, and } 5-21.5 \mathrm{~m} \\
\text { is strongly weathered rock. }\end{array}$ & $\begin{array}{l}\text { Water starts to flow out at } 12 \mathrm{~m} \text {, and the flow } \\
\text { is } 4.5 \mathrm{~L} / \mathrm{min} \text {. The water quality is clear. }\end{array}$ & $100 \%$ \\
\hline ZJ-14 & $\begin{array}{l}0-10 \mathrm{~m} \text { is dry soil, and } 10-12 \mathrm{~m} \\
\text { is strongly weathered granite. }\end{array}$ & Yellow mud flows out at $12-20 \mathrm{~m}$, and the flow is $3.6 \mathrm{~L} / \mathrm{min}$. & $100 \%$ \\
\hline
\end{tabular}

integrity and stability of surrounding rocks are improved, and the inflow of water in the tunnel is reduced, but there is still a large inflow of water in the face of the tunnel, and there is still a water-rich channel in the part, so it is necessary to carry out further grouting work to improve the effect of water plugging and reinforcement.

3.5.1. Implementation of Supplementary Grouting. According to the test results, there are two key points to supplement grouting. One is to strengthen the vault to ensure the stability of the original gushing water point of the vault and to form an effective stop-grouting rock disk in front of the gushing mud point and to solidify the collapsed soft soil. The second is to widen the lower range of the reinforcement section and effectively block the bedrock fissure water in the lower part to ensure the safety of later excavation. The main grouting parameters are similar to those of full-face curtain grouting.

In addition, a small number of grouting holes are arranged in the middle of the reinforcement section in order to preliminarily test the grouting effect and adjust the grouting pressure, slurry water-cement ratio, and other parameters according to the actual engineering geological conditions. This ensures the sealing effect of grouting and the normal excavation of the tunnel after grouting. The layout of supplementary grouting holes and the water inrush results of some holes are shown in Figure 16. 
3.5.2. Evaluation of Supplementary Grouting. After the completion of supplementary grouting, 7 test holes are drilled again to test the treatment effect of tunnel water gushing after the completion of supplementary grouting. The layout of detection holes is shown in Figure 17. The test results are shown in Table 4.

It is found in the test results that the yellow mud flow is found in some locations. However, it is analyzed from the site that the yellow mud mainly come from the completely weathered rock and the loose soil remaining after the early mud-bursting water in the fault zone, which is disturbed by the impact of drilling and flow out together with pore water. And the stability of the whole hole is still good. The overall detection results show that a certain amount of grouting stone framework is formed in the stratum after the grouting reinforcement so that the soil has a certain structure and self-stability. In addition, the water inflow is significantly reduced, which meets the requirements of the tunneling. The situation after grouting is completed is shown in Figure 18.

\section{Conclusions}

In water-rich and fully weathered granite areas, water and mud inrush will cause great harm to tunnel construction and the surrounding environment. The water and mud inrush disaster in Junchang tunnel is controlled, and the effect is studied systematically. The following conclusions can be drawn from this case study.

(i) Geological and hydrological conditions are reviewed to understand their impact on water and mud inrush disasters. Completely weathered granite has poor stability, rock strata are broken, and the topography is a miniature basin. Groundwater is abundant, rainfall is concentrated, and rainfall is large. The comprehensive influence of these factors is the possible cause of serious water inrush and mud inrush in Junchang tunnel

(ii) Full-section curtain grouting is used to block water. By combining exploration with injection, the former series of holes are used as exploration holes to master the properties of surrounding rocks and hydrogeological conditions in the treatment area, and different kinds of grout are used according to different hydrologic conditions. The latter sequence of holes also undertakes the task of checking the grouting effect of the former sequence holes, so as to timely understand the grouting effect of the earlier stage and optimize the grouting plan of the later stage

(iii) By means of Transient Electromagnetic Methods, water inflow analysis, borehole investigation, and $\mathrm{P}-\mathrm{Q}-\mathrm{T}$ method, the sealing effect of grouting is evaluated comprehensively. The results show that after grouting, the water content of palm surface decreases and the stability of soil layer increases, but there are still some areas rich in water and the water flow channel is not blocked. According to the test results, grouting can be added to the weak parts of grouting plugging. After grouting, the test is carried out again, and the results show that the curtain grouting method has a good effect of water stop reinforcement and meets the requirements of tunneling

\section{Data Availability}

The data used to support the findings of this study are available from the corresponding author upon request.

\section{Conflicts of Interest}

The authors declare that there is no conflict of interest regarding the publication of this paper.

\section{Acknowledgments}

This research was supported by the Hunan Water Conservancy Science and Technology Project (XSKJ2018179-40), the Fundamental Research Funds for Central Universities of the Central South University (2020zzts619), and the Research and Innovation Project for the Graduate Students of Hunan Province (CX20200349).

\section{References}

[1] J. L. Qiu, Y. Q. Lu, J. X. Lai, Y. Zhang, T. Yang, and K. Wang, "Experimental study on the effect of water gushing on loess metro tunnel," Environmental Earth Sciences, vol. 79, no. 11, 2020.

[2] X. Zhao and X. H. Yang, "Experimental study on water inflow characteristics of tunnel in the fault fracture zone," Arabian Journal of Geosciences, vol. 12, no. 13, 2019.

[3] J. H. Shin, K. C. Choi, J. U. Yoon, and Y. J. Shin, "Hydraulic significance of fractured zones in subsea tunnels," Marine Georesources \& Geotechnology, vol. 29, no. 3, pp. 230-247, 2011.

[4] C. L. Wang, Y. Zhao, Y. L. Zhao, and W. Wan, "Study on the interaction of collinear cracks and wing cracks and cracking behavior of rock under uniaxial compression," Advances in Civil Engineering, vol. 2018, Article ID 5459307, 10 pages, 2018.

[5] H. Lin, X. Zhang, Y. X. Wang et al., "Improved nonlinear Nishihara shear creep model with variable parameters for rock-like materials," Advances in Civil Engineering, vol. 2020, Article ID 7302141, 15 pages, 2020.

[6] X. P. Zhou, "Localization of deformation and stress-strain relation for mesoscopic heterogeneous brittle rock materials under unloading," Theoretical and Applied Fracture Mechanics, vol. 44, no. 1, pp. 27-43, 2005.

[7] X. P. Zhou and H. Q. Yang, "Dynamic damage localization in crack-weakened rock mass: strain energy density factor approach," Theoretical and Applied Fracture Mechanics, vol. 97, pp. 289-302, 2018.

[8] Y. L. Zhao, L. Y. Zhang, W. J. Wang, Q. Liu, L. Tang, and G. Cheng, "Experimental study on shear behavior and a revised shear strength model for infilled rock joints," International Journal of Geomechanics, vol. 20, no. 9, article 04020141, 2020. 
[9] X. P. Zhou, Y. X. Zhang, Q. L. Ha, and K. S. Zhu, "Micromechanical modelling of the complete stress-strain relationship for crack weakened rock subjected to compressive loading," Rock Mechanics and Rock Engineering, vol. 41, no. 5, pp. 747-769, 2008.

[10] Y. L. Zhao, Y. X. Wang, W. J. Wang, L. Tang, Q. Liu, and G. Cheng, "Modeling of rheological fracture behavior of rock cracks subjected to hydraulic pressure and far field stresses," Theoretical and Applied Fracture Mechanics, vol. 101, pp. 5966, 2019.

[11] S. J. Xie, H. Lin, Y. X. Wang et al., "A statistical damage constitutive model considering whole joint shear deformation," International Journal of Damage Mechanics, vol. 29, no. 6, pp. 988-1008, 2020.

[12] R. H. Cao, P. Cao, H. Lin, C. Z. Pu, and K. Ou, "Mechanical behavior of brittle rock-like specimens with pre-existing fissures under uniaxial loading: experimental studies and particle mechanics approach," Rock Mechanics and Rock Engineering, vol. 49, no. 3, pp. 763-783, 2016.

[13] R. H. Cao, P. Cao, X. Fan, X. G. Xiong, and H. Lin, “An experimental and numerical study on mechanical behavior of ubiquitous-joint brittle rock-like specimens under uniaxial compression," Rock Mechanics and Rock Engineering, vol. 49, no. 11, pp. 4319-4338, 2016.

[14] H. Lin, W. Xiong, Z. Y. Xiong, and F. Q. Gong, "Three-dimensional effects in a flattened Brazilian disk test," International Journal of Rock Mechanics and Mining Sciences, vol. 74, pp. 10-14, 2015.

[15] H. Lin, H. T. Yang, Y. X. Wang, Y. L. Zhao, and R. H. Cao, "Determination of the stress field and crack initiation angle of an open flaw tip under uniaxial compression," Theoretical and Applied Fracture Mechanics, vol. 104, p. 102358, 2019.

[16] H. Lin, W. Xiong, and Q. Yan, "Modified formula for the tensile strength as obtained by the flattened Brazilian disk test," Rock Mechanics and Rock Engineering, vol. 49, no. 4, pp. 1579-1586, 2016.

[17] Y. L. Zhao, L. Zhang, W. Wang, J. Tang, H. Lin, and W. Wan, "Transient pulse test and morphological analysis of single rock fractures," International Journal of Rock Mechanics and Mining Sciences, vol. 91, pp. 139-154, 2017.

[18] Y. L. Zhao, Y. Wang, W. Wang, W. Wan, and J. Tang, "Modeling of non-linear rheological behavior of hard rock using triaxial rheological experiment," International Journal of Rock Mechanics and Mining Sciences, vol. 93, pp. 66-75, 2017.

[19] Y. L. Zhao, L. Y. Zhang, J. Liao, W. Wang, Q. Liu, and L. Tang, "Experimental study of fracture toughness and subcritical crack growth of three rocks under different environments," International Journal of Geomechanics, vol. 20, no. 8, article 04020128, 2020.

[20] Y. L. Zhao, L. Zhang, W. Wang, W. Wan, and W. Ma, "Separation of elastoviscoplastic strains of rock and a nonlinear creep model," International Journal of Geomechanics, vol. 18, no. 1, article 04017129, 2018.

[21] J. H. Zhang, L. Y. Zhang, W. J. Wang, D. B. Zhang, and B. Zhang, "Probabilistic analysis of three-dimensional tunnel face stability in soft rock masses using Hoek-Brown failure criterion," International Journal for Numerical and Analytical Methods in Geomechanics, vol. 44, no. 11, pp. 1601-1616, 2020.

[22] J. H. Zhang and B. Zhang, "Reliability analysis for seismic stability of tunnel faces in soft rock masses based on a $3 \mathrm{D}$ stochas- tic collapse model," Journal of Central South University, vol. 26, no. 7, pp. 1706-1718, 2019.

[23] J. H. Zhang, W. J. Wang, B. Zhang, D. B. Zhang, and J. C. Song, "Upper bound solution for required supporting pressure applied on a deep shield tunnel face under different groundwater levels," Geotechnical and Geological Engineering, vol. 37, no. 1, pp. 491-499, 2019.

[24] J. H. Zhang, W. J. Wang, B. Zhang, and D. B. Zhang, "Upper bound analysis for collapse failure of shield tunnel face excavated in unsaturated soils considering steady vertical flow," Mathematical Problems in Engineering, vol. 2019, Article ID 2145616, 10 pages, 2019.

[25] J. H. Zhang, W. J. Wang, D. B. Zhang, B. Zhang, and F. Meng, "Safe range of retaining pressure for three-dimensional face of pressurized tunnels based on limit analysis and reliability method," KSCE Journal of Civil Engineering, vol. 22, no. 11, pp. 4645-4656, 2018.

[26] H. B. Fan, Y. H. Zhang, S. Y. He, K. Wang, X. Wang, and H. Wang, "Hazards and treatment of karst tunneling in Qinling-Daba mountainous area: overview and lessons learnt from Yichang-Wanzhou railway system," Environmental Earth Sciences, vol. 77, no. 19, 2018.

[27] Q. L. Cui, H. L. Wu, S. L. Shen, Z. Y. Yin, and S. Horpibulsuk, "Protection of neighbour buildings due to construction of shield tunnel in mixed ground with sand over weathered granite," Environmental Earth Sciences, vol. 75, no. 6, 2016.

[28] F. Arikan, R. Ulusay, and N. Aydin, "Characterization of weathered acidic volcanic rocks and a weathering classification based on a rating system," Bulletin of Engineering Geology and the Environment, vol. 66, no. 4, pp. 415-430, 2007.

[29] S. Ceryan, S. Tudes, and N. Ceryan, "A new quantitative weathering classification for igneous rocks," Environmental Geology, vol. 55, no. 6, pp. 1319-1336, 2008.

[30] Y. X. Wang, H. Zhang, H. Lin, Y. L. Zhao, and Y. Liu, "Fracture behaviour of central-flawed rock plate under uniaxial compression," Theoretical and Applied Fracture Mechanics, vol. 106, 2020.

[31] Y. X. Wang, H. Lin, Y. L. Zhao, X. Li, P. Guo, and Y. Liu, "Analysis of fracturing characteristics of unconfined rock plate under edge-on impact loading," European Journal of Environmental and Civil Engineering, vol. 19, pp. 1-16, 2019.

[32] Y. Zhao, P. F. Li, and S. M. Tian, "Prevention and treatment technologies of railway tunnel water inrush and mud gushing in China," Journal of Rock Mechanics and Geotechnical Engineering, vol. 5, no. 6, pp. 468-477, 2013.

[33] J. D. Niu, B. Wang, C. Feng, and K. Chen, "Experimental research on viscosity characteristics of grouting slurry in a high ground temperature environment," Materials, vol. 13, no. 14, p. 3221, 2020.

[34] J. D. Niu, B. Wang, G. J. Chen, and K. Chen, "Predicting of the unit grouting quantity in karst curtain grouting by the water permeability of rock strata," Applied Sciences, vol. 9, no. 22, p. $4814,2019$.

[35] Y. X. Wang, H. Zhang, H. Lin, Y. Zhao, X. Li, and Y. Liu, "Mechanical behavior and failure analysis of fracture-filled gneissic granite," Theoretical and Applied Fracture Mechanics, vol. 108, 2020.

[36] J. Q. Liu, W. Z. Chen, D. S. Yang, J. Yuan, X. Li, and Q. Zhang, "Nonlinear seepage-erosion coupled water inrush model for completely weathered granite," Marine Georesources and Geotechnology, vol. 36, no. 4, pp. 484-493, 2018. 
[37] J. Q. Liu, W. Z. Chen, T. G. Liu, J. Yu, J. Dong, and W. Nie, "Effects of initial porosity and water pressure on seepageerosion properties of water inrush in completely weathered granite," Geofluids, vol. 2018, Article ID 4103645, 11 pages, 2018.

[38] D. X. Liang, Z. Q. Jiang, S. Y. Zhu, Q. Sun, and Z. W. Qian, "Experimental research on water inrush in tunnel construction," Natural Hazards, vol. 81, no. 1, pp. 467-480, 2016.

[39] J. Q. Zhang, S. C. Li, Q. S. Zhang et al., "Mud inrush flow mechanisms: a case study in a water-rich fault tunnel," Bulletin of Engineering Geology and the Environment, vol. 78, no. 8, pp. 6267-6283, 2019.

[40] T. Yang, Q. S. Zhang, X. Zhang et al., "Cohesion variation during instability evolution of disaster medium in mud inrush of mountain tunnel," Journal of Mountain Science, vol. 16, no. 11, pp. 2519-2531, 2019.

[41] Y. L. Zhao and L. Y. Zhang, "Experimental study on the mudwater inrush characteristics through rock fractures," Advances in Civil Engineering, vol. 2018, Article ID 2060974, 7 pages, 2018.

[42] H. Y. Li, Y. Zhang, J. Wu, X. Zhang, L. Zhang, and Z. Li, "Grouting sealing mechanism of water gushing in karst pipelines and engineering application," Construction and Building Materials, vol. 254, 2020.

[43] L. C. Zou, U. Håkansson, and V. Cvetkovic, "Two-phase cement grout propagation in homogeneous water-saturated rock fractures," International Journal of Rock Mechanics and Mining Sciences, vol. 106, pp. 243-249, 2018.

[44] H. Stromsvik, "The significance of hydraulic jacking for grout consumption during high pressure pre-grouting in Norwegian tunnelling," Tunnelling and Underground Space Technology, vol. 90, pp. 357-368, 2019.

[45] H. Shi, M. Z. Bai, and S. C. Xing, "Mechanics parameter optimization and evaluation of curtain grouting material in deep, water-rich karst tunnels," Advances in Materials Science and Engineering, vol. 2017, Article ID 1853951, 12 pages, 2017.

[46] J. Q. Liu, W. Z. Chen, Z. P. Deng, T. Liu, and J. Dong, "Impacts of confining pressure and safety thickness on water and mud inrush in weathered granite," Marine Georesources \& Geotechnology, vol. 38, no. 2, pp. 144-153, 2020.

[47] W. H. Zheng, D. W. Wang, G. J. Li, L. Qin, K. Luo, and J. Liu, "Optimizing the grouting design for groundwater inrush control in completely weathered granite tunnel: an experimental and field investigation," Sustainability, vol. 11, no. 13, p. 3636, 2019.

[48] H. B. Lee, T. M. Oh, E. S. Park, J. W. Lee, and H. M. Kim, "Factors affecting waterproof efficiency of grouting in single rock fracture," Geomechanics and Engineering, vol. 12, no. 5, pp. 771-783, 2017.

[49] M. el Tani and H. Stille, "Grout spread and injection period of silica solution and cement mix in rock fractures," Rock Mechanics and Rock Engineering, vol. 50, no. 9, pp. 23652380, 2017.
[50] W. J. Zhang, S. Li, J. Wei et al., "Grouting rock fractures with cement and sodium silicate grout," Carbonates and Evaporites, vol. 33, no. 2, pp. 211-222, 2018.

[51] J. Q. Liu, W. Z. Chen, J. Q. Yuan, C. Li, Q. Zhang, and X. Li, "Groundwater control and curtain grouting for tunnel construction in completely weathered granite," Bulletin of Engineering Geology and the Environment, vol. 77, no. 2, pp. 515$531,2018$.

[52] J. Zhang, S. C. Li, Z. F. Li et al., "Grouting effect on reinforcement of weathered granite," Geotechnical and Geological Engineering, vol. 38, no. 3, pp. 2873-2886, 2020. 